\title{
UNSTEADY PERFORMANCE ANALYSIS OF A TWIN-ENTRY VARIABLE GEOMETRY TURBOCHARGER TURBINE
}

\author{
Srithar Rajoo ${ }^{\mathrm{a}}$, Alessandro Romagnoli ${ }^{\mathrm{b}}$ and Ricardo Martinez-Botas ${ }^{\mathbf{b}^{*}}$ \\ ${ }^{\mathrm{a}}$ Transportation Research Alliance, Universiti Teknologi Malaysia, 81310 UTM Skudai Johor, Malaysia \\ ${ }^{\mathrm{b}}$ Department of Mechanical Engineering, Imperial College London, SW7 2AZ Exhibition Road, London UK
}

\section{ABSTRACT}

The unsteady performance of a twin-entry variable geometry turbine for an automotive turbocharger is presented. A single-entry variable geometry turbine was initially designed based on a commercial nozzle-less turbine. The variable geometry single-entry volute was later modified to twin-entry through partitioning. A comprehensive range of steady testing and evaluation was also conducted as part of this project, which is discussed by Romagnoli et al. [1]. The unsteady curves of the twin-entry turbine exhibited the conventional looping characteristics representing filling and emptying effects, which was also the case for the nozzleless and single-entry nozzled turbine. The swallowing capacity of the twin-entry turbine, during full admission testing, was recorded to be inconsistent between the two entries, in particular they were at different pressure ratio levels - the shroud end entry was in most cases more pressurized compared to the hub end entry, as much as 13\%. Contrarily, during out-of-phase testing the swallowing capacity of both the turbine entries was found to be similar. The cycle-averaged efficiency of the nozzled turbine either twin or singleentry was found to depart significantly from the equivalent quasi-steady, in comparison to the nozzleless single-entry turbine, this was as much as $32 \%$.

\footnotetext{
*corresponding author

Ricardo Martinez-Botas, r.botas@imperial.ac.uk | Tel : +44 (0) 2075947241 | Fax : +44 (0) 2078238845

Emails : srithar@fkm.utm.my (Srithar Rajoo) and a.romagnoli@imperial.ac.uk (Alessandro Romagnoli)
} 


\section{NOMENCLATURE}

C Absolute velocity, $\mathrm{m} / \mathrm{s}$

D Rotor Diameter, $\mathrm{m}$

MFP Mass flow parameter, $\mathrm{kg} \sqrt{ } \mathrm{K} / \mathrm{Pa}$

N Turbine speed, RPS

$\mathrm{P} \quad$ Pressure, $\mathrm{Pa}$

PR Pressure ratio

$\mathrm{T} \quad$ Temperature, $\mathrm{K}$

U Rotor tip velocity, $\mathrm{m} / \mathrm{s}$

$\dot{m} \quad$ Mass flow rate, $\mathrm{Kg} / \mathrm{s}$

$\dot{W} \quad$ Power, $\mathrm{kW}$

$\eta \quad$ Efficiency $\theta \quad$ Phase Angle

\section{Subscript}

actual actual conditions

ins instantaneous conditions

isent isentropic

ts $\quad$ total to static

O Total conditions

$1 \quad$ Turbine stage inlet

$5 \quad$ Turbine stage exit

\subsection{INTRODUCTION}

A turbocharger turbine operates under unsteady conditions due to the pulsating nature of the exhaust gases. In consequence, twin-entry turbines are generally designed and used for better energy extraction from the pulsating exhaust gases. Two banks of exhaust manifolds feed each entry of the turbine so that the "rotor windmill" is minimized as the mass flow drops to zero. Thus, there is a need for experimental work to understand the unsteady-state performance of a twin-entry turbine in comparison to the single-entry and nozzleless unit.

Wallace and Blair [2] and Benson and Scrimshaw [3] presented the earliest systematic study on the unsteady performance of a radial turbine. These were followed by Wallace et al. [4], Miyashita et al. [5], Benson [6] and Kosuge et al. [7]. All these investigations were limited by the inability of the instruments to instantaneously measure all the relevant performance parameters. Thus, only the static pressure was measured instantaneously, while the mass flow rate, temperature, speed and torque were measured as time-mean values. This remains similar for the investigation presented by 
Capobianco et al. [8,9] and Capobianco and Gambarotta [10]. Research work by Capobianco et al. $[8,9]$ concentrated on establishing correlations between the unsteady parameter and the equivalent steady values. However, as only the pressure measured instantaneously, all comparative parameters were assessed through quasi-steady approach. Winterbone et al. [11] and Winterbone and Pearson [12] presented a good review of the experimental techniques and understanding of the pulsating flow performance of a turbocharger turbine.

Dale and Watson [13] and Dale [14] were the earliest to present an unsteady performance data for a turbine with all the parameters measured instantaneously (except instantaneous temperature). A radial twin-entry nozzleless turbine was used to investigate the performance characteristics under steady, unsteady, equal admission and partial admission conditions. Dale [14] presented results for pulse frequency of 40 and $60 \mathrm{~Hz}$, turbine speed $300-700$ RPS, a mean total inlet temperature of $400 K$ and a maximum instantaneous pressure ratio of 1.8 . The turbine was coupled to an eddycurrent dynamometer with a loading capacity of $12 \mathrm{~kW}$. Dale and Watson [13] measured the instantaneous mass flow rate at the turbine inlet with a hot-wire anemometry and the instantaneous inlet static pressure with a fast response pressure transducer. The torque was deduced from the rotor rotational speed and acceleration. Almost all researchers investigating the unsteady performance of a radial/mixed flow turbine have used these measurement techniques ever since. Based on the instantaneous measurement, Dale and Watson [13] presented the typical hysteresis loop for radial turbine unsteady performance curves. Nikpour [15] conducted a study similar to Dale [14] but with a nozzleless turbine. A hydraulic dynamometer was used to load the turbine with higher maximum speed compared to Dale [14]. A hysteresis loop was also recorded for the unsteady performance curve, but with greater deviation from the equivalent steady, compared to Dale [14].

Baines et al. [16] further developed the work by Dale and Watson [13] with the study of a twinentry nozzleless radial turbine under pulsating flow conditions. The measuring instruments remain largely similar to Dale and Watson [13]. The turbine performances were evaluated for pulse frequency of 20, 40 and $60 \mathrm{~Hz}$, turbine speed of $300-500$ RPS, a mean total inlet temperature of 
$400 \mathrm{~K}$ and a maximum instantaneous pressure ratio of 1.8. Baines et al. [16] also documented the out-of-phase pulsating flow results, where dual-loops in the instantaneous efficiency trace were found. These were attributed to the effect of reverse flow from the open valve limb to the close valve limb in an out-of-phase testing. In overall, the similar hysteresis loops in the unsteady performance curves were found as other researchers. The experimental facility in the current study is an improved version from Dale and Watson [13] and Baines et al. [16].

\subsection{EXPERIMENTAL FACILITY}

Fig. 1 illustrates the turbine configurations used for the current study, which was designed in progression from nozzleless single-entry to nozzled twin-entry. The details of the turbine design stages are described in Romagnoli et al. [1]. The experimental facility available in Imperial College London is a simulated reciprocating engine test-bed for turbocharger testing. The facility has the capability of conducting steady and unsteady flow testing of single and twin-entry turbines. A schematic diagram of the turbine test rig is shown in Fig. 2. The test rig is equipped with an eddy current dynamometer, which enables turbine testing within a large velocity ratio range $[7,8]$. The test-rig is supplied by screw-type compressors, capable to delivering air up to $1.2 \mathrm{~kg} / \mathrm{s}$ mass flow rate at a maximum pressure of 5 bars (absolute). The two separated streams of airflow in each limb pass through a rotary air pulse generator, which consists of two rotating chopper plates as shown in Fig. 3. The chopper plates consist of unique cut outs, which were originally designed by Dale and Watson [13] to experimentally simulate the exhaust gas pulsation of an engine as shown in Fig. 3. A variable speed D.C. motor controls the rotating frequency of the chopper plates, hence the frequency of the pulsation. The phase of the entry pulses in both the limbs can be varied either to be in-phase or out-of-phase by changing the relative position of the two chopper plates. 


\subsection{UNSTEADY TESTING AND ANALYSIS PROCEDURES}

The conditions for the unsteady test points are set up to correspond to the steady-state velocity ratio at peak efficiency for a given speed. This is achieved by comparing the energy averaged velocity ratio at unsteady flow condition, with the steady-state velocity ratio at peak efficiency. Once the desired condition is achieved and the system stabilizes, measurements of pressures, temperatures, mass flow rate, speed and torque are acquired instantaneously with reference to chopper plate frequency. A pulse signal produced once per revolution by the chopper plate is used as trigger to concurrently measure all the parameters.

The instantaneously acquired data points are processed in few stages before it can be used to calculate the performance parameters. Hot-wire anemometer used to measure mass flow rate is set to traverse and measure at 36 locations in the pipe cross section. Meanwhile the data logging system is set to acquire 50 cycles of data for each location. Thus, a total of 1800 cycles are recorded for every test point during unsteady experiments. For all but the hotwire measurement, the 1800 cycles are ensemble averaged to reduce any random non-cyclic fluctuation in the measurement. Meanwhile the 36 points hotwire measurements are integrated as specified in BS 1042:1983 and only 50 cycles are ensemble averaged. The hotwire measurement is then corrected for temperature before the final mass flow rate can be deduced. The instantaneous temperature of the flow is calculated based on the isentropic compression assumption. The ensemble averaged signals are then filtered with Finite Impulse Response (FIR) to further attenuate noises in the reading.

All but the speed signals are recorded with an analogue-digital card with constant sampling rate of 20,000 samples per second. The speed signal is logged through a counter card, thus the recorded number of samples per cycle are not constant and not in match with the analogue readings. For the purpose of instantaneous point-by-point analysis, the speed signal is resample at a constant 20,000 samples per second with spline interpolation. The speed signal is then derived to determine the fluctuating torque of the rotor. Consequently the fluctuating torque is used to calculate the total power of the turbine. The difference in the measurement locations of the actual and isentropic 
properties requires a degree of phase shifting to enable evaluation on common time frame. This is achieved by phase-shifting all the measurement to a common reference location using bulk + sonic flow velocity as described by Szymko et al. [17].

\subsection{UNSTEADY PERFORMANCE PARAMETERS}

Mass Flow Parameter vs. Pressure Ratio - The definition of the mass flow parameter and pressure ratio follows the conventional turbomachinery method, with instantaneous time varying individual components for each property. Mass flow parameter is a pseudo-dimensionless parameter derived by relating the inlet flow velocity and the inlet Mach number, as given in eq. (1). For the twin-entry turbine the mass flow parameter is calculated considering the contribution of each limb on the overall flow capacity. The mass flow leaving the two entries mixes prior entering to the rotor and it is therefore sensible to consider an average of the flow properties. From the energy equation, the stagnation temperature is calculated as a mass weighed average value while for the total pressure at inlet, an area average value is more appropriate. The final equation for the pseudo-dimensionless mass flow parameter in a twin-entry turbine is therefore given in eq. (2), where $\dot{m}_{\text {ins,tot }}=\dot{m}_{\text {ins,in }}+\dot{m}_{\text {ins,out }}$.

$M F P_{\text {ins }, S E}=\frac{\dot{m}_{\text {ins }} \sqrt{T_{01_{\text {ins }}}}}{P_{01_{\text {ins }}}} \quad$ (1) $\quad M F P_{\text {ins }, T E}=\dot{m}_{\text {ins }, \text { tot }} \cdot \frac{\sqrt{\frac{\dot{m}_{\text {ins }, \text { in }}}{\dot{m}_{\text {ins, tot }}} T_{01_{\text {ins }, \text { in }}}+\frac{\dot{m}_{\text {ins }, \text { out }}}{\dot{m}_{\text {ins }, \text { tot }}} T_{01 \text { ins }, \text { out }}}}{0.5\left(P_{01_{\text {ins }, \text { in }}}+P_{\left.01_{\text {ins }, \text { out }}\right)}\right)}$

The instantaneous pressure ratio is given in eq. (3). In a twin-entry turbine, the pressure ratio can be defined using an area averaged pressure ratio between the two entries as given in eq. (4).

$$
P R_{\text {ins }, S E}=\frac{P_{01_{\text {ins }}}}{P_{5_{\text {ins }}}} \quad \text { (3) } P R_{\text {ins }, T E}=\frac{1}{2}\left(\frac{P_{01_{\text {ins }, \text { in }}}}{P_{5_{\text {ins }}}}+\frac{P_{01_{\text {ins }, \text { out }}}}{P_{5_{\text {ins }}}}\right)
$$

Efficiency vs. Velocity Ratio - The turbine instantaneous total-to-static efficiency for a single-entry turbine is given in eq. (5). In the twin-entry cases instead, since power is an extensive quantity, the 
instantaneous total-to-static efficiency can be calculated considering the sum of the instantaneous isentropic power of the entries, as given in eq. (6).

$$
\left(\eta_{t s}\right)_{i n s, S E}=\frac{\dot{W}_{\text {actual }_{\text {ins }}}}{\dot{W}_{\text {isent }_{\text {ins }}}}
$$

$$
\left(\eta_{t s}\right)_{\text {ins,TE }}=\frac{\dot{W}_{\text {actual } i n s}}{\left(\dot{W}_{\text {isent }, \text { in }}+\dot{W}_{\text {isent,out }}\right)_{\text {ins }}}
$$

The instantaneous velocity ratio is the ratio between the rotor tip speed and the inlet isentropic velocity. The formulation of the instantaneous velocity ratios for the single and twin-entry turbine is given in eq. (7) and eq. (8) respectively.

$$
\left(\frac{U}{C_{\text {isent }}}\right)_{\text {ins,SE }}=\frac{\pi D N_{\text {ins }}}{\sqrt{\frac{2 \dot{W}_{\text {isent }} \dot{m}_{\text {ins }}}{\dot{m}_{\text {ins }}}}} \quad \text { (7) } \quad\left(\frac{U}{C_{\text {isent }}}\right)_{\text {ins, }, T E}=\frac{\pi D N_{\text {ins }}}{\sqrt{\frac{2\left(\dot{W}_{\text {isent }, \text { in }}+\dot{W}_{\text {isent }, \text { out }}\right)_{\text {ins }}}{\dot{m}_{\text {ins }, \text { tot }}}}}
$$

\subsection{RESULTS AND DISCUSSIONS}

\subsection{Comparing the single-entry nozzled to a nozzleless turbine}

Fig. 4 shows the plots of the turbine's swallowing capacity with nozzled single-entry and nozzleless volutes, for $40 \mathrm{~Hz}$ and $60 \mathrm{~Hz}$ flow and $80 \%$ equivalent speed. The nozzled turbine loops shown are for $50^{\circ}$ vane angle setting, which has similar swallowing capacity as with the nozzleless turbine. The equivalent quasi-steady curve of the nozzleless turbine is also shown on each plot. The loop of the nozzleless turbine shows better encapsulation of the equivalent quasi-steady curve, even though the range reduces at higher frequency. Furthermore, the hysteresis loop of the nozzleless turbine shows a clear sign of increasing wave action effect at higher flow frequency since if there was a predominance of filling and emptying effects one would have seen a more regular shape in the parts of the hysteresis shape. Wave action effect can be defined as a continuous interaction between the travelling pulses and the reflected pulses in a turbine flow system. This could be clearly observed as increasing perturbation in the recorded instantaneous pressures as well as instantaneous mass flow parameters. Concurrently, the travelling flow is also leaving the turbine as it enters, but at a 
different rate, which is defined as filling and emptying effect. It has been shown in many previous works that there is a strong link between the pulse flow frequency and the dominance of either wave action or filling emptying effect. Compared to the nozzleless turbine, the hysteresis loop of the nozzled turbine shows stronger sign of filling and emptying effect even at higher flow frequency. This is possibly due to the bigger volume and the existence of the nozzle ring, which effectively creates an intermediate volume with its own filling/emptying characteristics. Thus the effect of different measurement locations in a pulsating flow test is more pronounced in the nozzled turbine.

Fig. 5 shows the plots of the turbine instantaneous efficiency in a pulse cycle for the nozzled and nozzleless volutes. The shown curves are for different vane angle settings (plots $(c)$ and $(d)$ ), different frequencies (plot $(b)$ ) and $80 \%$ equivalent speed. The efficiency changes over a pulse cycle show a trend of improvement with the increase in flow frequency. This is observed in both the nozzled and nozzleless turbines, but marginally more significant in the latter. It can be noticed that the nozzleless turbine exhibit more negative efficiencies at the beginning and end of a cycle, which is the low pressure ratio region. It is more pronounced at lower flow frequency, which is also seen in the nozzled setting but with lesser effect. In the nozzled settings, the turbine did not exhibit negative efficiency at close nozzle positions $\left(70^{\circ}\right.$ and $\left.65^{\circ}\right)$. This is due to the nozzle constantly providing sufficient flow momentum to the rotor during the pulse cycle. But at a more open positions especially at $40^{\circ}$ and $50^{\circ}$ vane angle settings, the turbine gradually exhibit negative efficiency. This reflects the decrease in the tangential flow velocity at open nozzle positions in the low pressure ratio region. It is also noticed that during the first $120^{\circ}$ crank angles, where most of the isentropic power concentrated in the pulse, both the nozzleless and nozzled turbines shows no significant difference in most cases. The nozzled turbine shows increasing departure from the nozzleless unit at closer nozzle settings, which can be explained as the effect of choking and mass accumulation. Table 1 shows the velocity ratio, cycle-averaged efficiency and the equivalent quasisteady efficiency for the nozzleless turbine at different flow frequencies shown in Fig. 5(a). The overall efficiency characteristics with flow frequency are similar in both nozzleless and nozzled 
turbines. The departure of the unsteady cycle-averaged efficiency from the equivalent quasi-steady is more pronounced at lower flow frequencies. Marginal unsteady cycle-averaged efficiency improvement is recorded for higher flow frequencies. Nevertheless, the degree of departure of the unsteady conditions from the equivalent quasi-steady is more pronounced in the nozzled turbine, especially at higher vane angle settings.

Strouhal number is generally used to quantify the level of unsteadiness in the overall turbine volume (volute + pipe). This is defined as the ratio between the centrifugal force and the inertial force of a periodic flow [18] and it is used to evaluate the rate of localized changes of a moving particle in comparison to its propagation. In its original formulation, the Strouhal number was introduced for periodic flows only. However since the pulse waveform is not sinusoidal, the general equation is modified to take into account the pulse fraction and the gas velocity, $C$, which is added to the local sonic speed, $a$, to represent the velocity at which the pressure waves are propagated. One thus arrives to the so-called pressure modified Strouhal number [19] defined in eq. (9).

$$
\text { PMSt. }=\frac{f \cdot L}{C+a} \cdot \frac{1}{2 \varphi}
$$

where $f$ is the flow frequency, $L$ the characteristic length taken as the distance from the measurement plane to a nominal energy entry point into the rotor (in this case at $180^{\circ}$ azimuth angle) and, $1 / 2 \varphi$ is used to normalise the waveform of the pulse feeding the turbine [20].

The unsteady swallowing capacity curves (Fig. 4) show that the nozzled turbine exhibits more of a filling and emptying characteristics in both the flow frequencies; this was also the case for higher flow frequency and especially closer nozzle positions. This does not correspond well to the value of pressure modified Strouhal number above 0.1 for higher frequency conditions, which indicates a fully unsteady regime [21]. On the other hand, the unsteady curves of a nozzleless turbine exhibit better correlation with the pressure modified Strouhal number. This can be due to the larger volume 
in the nozzled turbine ( $48 \%$ bigger volume) and to the lower swallowing capacity of the nozzled turbine (at closed position), which leads to mass accumulation and possible choking.

\subsection{Swallowing capacity of twin-entry turbine}

The nozzled single-entry turbine is converted into twin-entry through partitioning as described in Romagnoli et al. [1]. The twin-entry turbine is tested under pulsating flow with in-phase and $180^{\circ}$ out-of-phase flow admission conditions. The typical inlet static pressure profiles during in-phase and $180^{\circ}$ out-of-phase conditions for various flow frequencies and speed are given in Fig. 6 . The inner and outer limb notations in the figure refer to the individual inlet of the twin-entry turbine, shown in Fig. 2. The inlet conditions are monitored throughout the experimental process to ensure a consistent phase between the limbs, as this affects the post processing for performance analysis.

Figs. $7 \& 8$ show the swallowing capacity of the twin-entry turbine during in-phase full admission test at $50 \%$ and $80 \%$ equivalent speed conditions respectively. In both the figures, results for $40 \mathrm{~Hz}$ and $60 \mathrm{~Hz}$ pulsating flow conditions are shown, as well as the equivalent quasi-steady curves for the partial admissions. The swallowing capacity of the individual limbs is shown and the overall swallowing capacity of the turbine calculated with mass averaged inlet total temperatures and pressures. The common looping curves are observed in all the cases, with some degree of encapsulation around the quasi-steady curves; due to continuous filling and emptying of the volume during pulsating flow conditions. It can be seen that the outer limb swallowing capacity tends toward steady characteristics during the $50 \%$ speed, but falls below the equivalent quasi-steady. However during $80 \%$ speed condition, it shows clear looping characteristics around the steady curve. Comparing the swallowing capacity between $50 \%$ and $80 \%$ speeds, it can be seen that the turbine swallows more compared to the equivalent steady at higher speed conditions. The cycleaveraged unsteady mass flow parameter at $40 \mathrm{~Hz} 80 \%$ speed is around $38 \%$ higher than the cycle averaged steady condition. As for $60 \mathrm{~Hz} 80 \%$ condition the number is approximately $60 \%$. 
Another observation is that the pressure ratio range during a cycle in pulsating flow emulates the steady curves more in the $80 \%$ compared to the $50 \%$ speed. Comparing the individual limbs, the swallowing capacity of the inner limb is consistently at the lower end of pressure ratio, this is more apparent in the $50 \%$ speed conditions. The unsteady swallowing capacity curves at different conditions in Figs. $7 \& 8$ show that the twin-entry turbine exhibits more of a filling and emptying characteristics. This is consistent with the observed characteristics of the single-entry nozzled turbine (Fig. 4).

Fig. 9 shows the swallowing capacity of the twin-entry turbine under unequal $180^{\circ}$ out-of-phase flow condition, for $40 \mathrm{~Hz}$ and $60 \mathrm{~Hz}$ pulsations. The swallowing capacity of the individual entry shows clear filling and emptying effect for all conditions, with almost full encapsulation of the steady curves. The calculation of the overall swallowing capacity of the twin-entry turbine is not straightforward in an unequal flow conditions. Mass averaging the pressure ratios of the two entries will reduce the range covered during a cycle, compared to the individual entry. This can be seen clearly in Fig. 9, as well as the double looping in the overall swallowing capacity representing both entries.

\subsection{Power and efficiency of twin-entry turbine}

Fig. 10 shows the isentropic and actual power curves of the twin-entry turbine under different conditions. The actual power is calculated from the measured rotor torque and speed, while the isentropic power calculated with measured upstream parameters. In general, the turbine power is found to be similar for both the entries. A good correlation is observed between the isentropic and actual power, given the separate deriving technique for both. It can be seen that at some instances the actual power of the turbine goes negative; this is explained in Szymko et al. [17] as the conditions where the turbine rotor imparts momentum on the flow due to a very low energy content of the free stream. Interestingly such condition does not occur for out-of-phase flow, indicating better flow momentum with 2 pulses per cycle. In addition, Fig. 10 also shows that the isentropic 
power at $60 \mathrm{~Hz}$ and $80 \%$ speed under full admission does not show a clear peak as expected. Instead, the isentropic power remains fairly flat over the whole pulsation period, which results in poor turbine instantaneous efficiency representation for majority of the pulse period. However, the instantaneous pressure profile, as shown in Fig. 6, does not show a similar plateauing trend. This seems to suggest mass accumulation effect due to the existence of nozzle between the volute and rotor. This effect is clearly dominating at the higher frequency, as it was observed even at $80 \mathrm{~Hz}$ (not discussed here). At higher frequency, the emptying rate of the nozzled turbine system is not capable to cope with the filling rate, thus resulting in mass accumulations. However this is not observed at out-of-phase conditions, as the amount of mass entering the turbine system is staggered, resulting in better emptying process.

The comparison of the actual and isentropic power of the turbine will enable the derivation of efficiency however instantaneous comparison creates a level of complexity. This is due to factors affecting the comparison mainly the phase shifting due to different measurement locations. There are still debates on the effective method of defining the efficiency of a turbine under unsteady flow conditions [21].

\subsection{Cycle averaging and comparison to quasi-steady}

Given the uncertainty associated with the meaning of the instantaneous turbine efficiency, an alternative method to evaluate energy conversion is by cycle averaging the parameters. The main advantage of the cycle-averaging method is that it is not affected by phase shifting. The cycleaveraged efficiency represents the ratio of energy extracted by the turbine per pulse cycle divided by isentropic energy flowing into the system, as given in eq. (10).

$$
\left(\eta_{t s}\right)_{\text {energy-avg }}=\frac{\int_{0}^{\theta}\left[\eta_{t s} \cdot \dot{W}(t)_{\text {isent }}\right] d t}{\int_{0}^{\theta} \dot{W}(t)_{\text {isent }} d t}=\frac{\int_{0}^{\theta}\left[\dot{W}(t)_{a c t}\right] d t}{\int_{0}^{\theta} \dot{W}(t)_{\text {isent }} d t}=\left(\eta_{t s}\right)_{\text {cycle-avg }}
$$


The velocity ratio is calculated with energy weighed averaging as shown in eq. $(11)^{1}$,

$$
\left(\frac{U}{C_{\text {isent }}}\right)_{\text {energy-avg }}=\frac{\int_{0}^{\theta}\left[\frac{U}{C_{i s e n t}}(t) \cdot \dot{W}(t)_{i s e n t}\right] d t}{\int_{0}^{\theta} \dot{W}(t)_{i s e n t} d t}
$$

The calculated energy weighed cycle-averaged velocity ratio is then used to read the corresponding efficiency from the steady map for that given speed. The cycle-averaged efficiency is then compared with the equivalent quasi-steady efficiency. By doing this an appropriate comparison between parameters obtained at different conditions can therefore be performed.

Table 2 reports a comparison between the cycle-averaged and the quasi-steady efficiency obtained for $60^{\circ}$ vane angle at $50 \%$ and $80 \%$ equivalent speeds under in-phase and out-of-phase flow, for $40 \mathrm{~Hz}, 60 \mathrm{~Hz}$ and $80 \mathrm{~Hz}$ frequencies. It is worth noting that the full admission assumption has been considered here for the quasi-steady value. This is appropriate when dealing with in-phase flow (since both entries flow concurrently) while further analysis would be required for the out-of-phase flow condition (since each limb is pressurized at staggered intervals).

Figs. $11 \& 12$ show the efficiency comparison for the in-phase and out-of-phase flow respectively. Observing the comparison, one can notice that the cycle-averaged unsteady efficiency drops substantially, especially for the in-phase flow and lower speed conditions. The cycle-averagedefficiency remains below the quasi-steady efficiency with a difference of $26.2 \%, 26.4 \%$ and $0.79 \%$ for $40 \mathrm{~Hz}, 60 \mathrm{~Hz}$ and $80 \mathrm{~Hz}$ respectively. At higher speed instead, the discrepancy is less significant and in some cases the quasi-steady efficiency is higher than the cycle-averaged efficiency. This occurs at $80 \mathrm{~Hz}$ and $40 \mathrm{~Hz}$ where the cycle-averaged efficiency is $5.1 \%$ and $6.1 \%$ higher than the quasi-steady. At high frequency the similarity between the cycle-averaged and the quasi-steady efficiency can be explained considering that the pulse amplitude is smaller which makes the rotor exposed to more continuous flow. At lower frequency instead, the flow follows a filling and emptying behaviour, thus significant swallowing capacity changes are experienced leading to the

\footnotetext{
${ }^{1}$ In a twin-entry configuration $\dot{W}_{\text {isent }}=\dot{W}_{\text {isent, in }}+\dot{W}_{\text {isent,out }}$, while the velocity ratio $U / C_{\text {isent }}$ is equal to that provided in eq. (8).
} 
differences between the cycle-averaged and quasi-steady efficiencies. Similar results were also shown by Karamanis and Martinez-Botas [22], Szymko et al. [17] and Rajoo and Martinez-Botas [21], who measured higher cycle-averaged efficiency in a single-entry turbine for higher speeds and frequencies. However, it must be noted that no consistent trend was observed in the cycle-averaged efficiency variation. In the out-of-phase flow conditions, the cycle-averaged efficiency shows large discrepancies from the quasi-steady - at $50 \%$ equivalent speed a difference of $23.1 \%, 30.3 \%$ and $18.0 \%$ was measured at $40 \mathrm{~Hz}, 60 \mathrm{~Hz}$ and $80 \mathrm{~Hz}$ respectively. A similar drop was also found at $80 \%$ equivalent speed - the cycle-averaged efficiency deviates from the quasi-steady by $18.2 \%, 32.2 \%$ and $27.1 \%$ for the $40 \mathrm{~Hz}, 60 \mathrm{~Hz}$ and $80 \mathrm{~Hz}$ cases respectively.

Another interesting aspect to taken into account is the effect of the pulsed flow phases (in-phase or out-of-phase) on the efficiency. From Table 2 it can be seen that the out-of-phase condition is detrimental to the overall efficiency above all at high speed. At $80 \%$ equivalent speed, the cycleaveraged efficiency drops from $0.835,0.616$, and 0.823 down to $0.631,0.520$, and 0.560 for $40 \mathrm{~Hz}$, $60 \mathrm{~Hz}$ and $80 \mathrm{~Hz}$ respectively, from the in-phase to out-of-phase flow condition - this corresponds to a drop of $32.2 \%, 18.4 \%$, and $46.9 \%$ respectively. However, the same deficit is not observed at lower speed where the efficiency drop is much lesser. At $50 \%$ equivalent speed, the efficiency drops from $0.472,0.456$ and 0.631 to $0.434,0.415$ and 0.526 (corresponding to a drop of $8.75 \%$, $9.8 \%$ and $19.96 \%$ ) for $40 \mathrm{~Hz}, 60 \mathrm{~Hz}$ and $80 \mathrm{~Hz}$ respectively, from the in-phase to out-of-phase flow condition.

In order to further understand the correlation between the cycle-averaged and the quasi-steady assumption, the ratios between these efficiencies has been calculated for both in-phase and outphase flow at $50 \%$ and $80 \%$ equivalent speeds. The parameter called efficiency ratio is plotted in Fig. 13 against pulse frequency $(40 \mathrm{~Hz}, 60 \mathrm{~Hz}$, and $80 \mathrm{~Hz})$. As noted from Fig. 13, at $80 \%$ equivalent speed, the efficiency ratio for the in-phase flow does not vary substantially with frequency, which goes in favour of the quasi-steady assumption. The dip observed at $60 \mathrm{~Hz}$ (efficiency ratio $\approx 0.8$ ) can 
be considered as the result of the transition through a region where the quasi-steady assumption no longer applies. In the out-of-phase flow conditions instead the efficiency ratio remains below unity for both $50 \%$ and $80 \%$ equivalent speeds.

In order to understand the efficiency trends, the unsteady time-averaged power and mass flow were calculated and compared to the quasi-steady values - these are shown in Fig. 14 for $80 \%$ speed. The quasi-steady values are obtained from the steady curves at the equivalent unsteady isentropic energy averaged velocity ratio. The figure show shat the quasi-steady average values generally over predict the corresponding unsteady values since the power and mass flow ratio remain below unity. The mass flow and power vary in a consistent manner for both in-phase and out-of-phase flow conditions - a decreasing value in the ratio observed with increasing frequency. Despite the similarities existing between the in-phase and out-of-phase power and mass flow ratios, Fig. 14 shows that in out-of-phase flow condition, the mass flow ratio (and hence the isentropic power ratio) is approximately equal to unity for almost any frequency, thus showing that the quasi-steady assumption is adequate for a full unsteady calculation. The same does not occur for the in-phase conditions for which a dip at $60 \mathrm{~Hz}$ can be observed in the mass flow and isentropic power ratio. As already observed before (Fig. 10) such a dip could be attributed to the increasingly unsteady correlations between the wave action and filling and emptying effects in the nozzled turbine system. On the efficiency side, the trend observed for the ratios between the cycle-averaged and the quasisteady efficiencies (Figs. $11 \& 12$ ) are reflected in the actual and isentropic power ratios - the isentropic power ratios remains consistently above the actual power ratio.

Comparing the cycle-averaged efficiency with the quasi-steady assumption based on full admission conditions is not conclusive when dealing with twin-entry turbines. It is a known fact that the twinentry turbine is meant to work in out-of-phase flow conditions in most cases. The incoming pulses from each bank of manifolds occur at staggered intervals, thus the turbine works in partial admission conditions in most cases compared to full admission. Therefore, in order to evaluate the quasi-steady assumption in the out-of-phase flow conditions, it is appropriate to refer to the partial 
admission maps instead of the full admission. Table 3 shows the quasi-steady efficiency calculated using the full and partial admission conditions. The cycle-averaged efficiencies and the ratio between the cycle-averaged and the quasi-steady efficiencies are shown in Fig. 15. From Fig. 15 it can be seen that the ratio between the cycle-averaged and the quasi-steady assumption based on the partial admission condition is much closer to unity compared to the cases where the full admission map is used (see Fig. 13). At $80 \%$ equivalent speed, the quasi-steady efficiency goes from 0.768 , 0.763 and 0.757 to $0.530,0.533$ and 0.534 for the $40 \mathrm{~Hz}, 60 \mathrm{~Hz}$ and $80 \mathrm{~Hz}$ cases respectively, considering the full to partial admission condition - such a drop leads to values of the efficiency ratio (in partial admission) to be $1.03,0.85$ and 0.92 for $40 \mathrm{~Hz}, 60 \mathrm{~Hz}$ and $80 \mathrm{~Hz}$ respectively. At $50 \%$ equivalent speed, the ratio between the cycle-averaged and quasi-steady efficiency is approximately $10 \%$ higher than that calculated considering the full admission curve, which results in an improvement in the evaluation of the quasi-steady assumption. In summary, the quasi-steady efficiency shifts from $0.647,0.586$ and 0.641 to $0.607,0.607$ and 6.08 for the $40 \mathrm{~Hz}, 60 \mathrm{~Hz}$ and $80 \mathrm{~Hz}$ cases respectively, considering the full admission to the partial admission case.

Table 4 shows the velocity ratio, cycle-averaged efficiency at $50 \%$ equivalent speed for different vane angle settings $\left(40^{\circ}, 60^{\circ}, 70^{\circ}\right)$ and flow frequencies $(40 \mathrm{~Hz}, 60 \mathrm{~Hz}$ and $80 \mathrm{~Hz})$ - these are plotted in Fig. 16. The values are energy weighed average as shown in eq. (5) and eq. (6). It can be noticed that the trend of the cycle-averaged efficiency for different vane angles does not seem to follow a well defined pattern. For the in-phase flow, the cycle-averaged efficiency shows about 12 percentage points drop from $40^{\circ}$ to $60^{\circ}$ vane angle for $40 \mathrm{~Hz}$ and $60 \mathrm{~Hz}$. This can be directly linked to the high fluctuation of the torque exhibited by the turbine for open vane angles compared to the closed vane settings which leads to higher cycle-averaged efficiency [21]. For $70^{\circ}$ vane angle and in-phase flow $40 \mathrm{~Hz}$ and $60 \mathrm{~Hz}$, the cycle-averaged efficiency is similar to that calculated for the $60^{\circ}$ vane angle even though a large departure from one another could be observed at $80 \mathrm{~Hz}$. A different scenario can be observed for the out-of-phase flow. The cycle-averaged efficiency increases with increasing frequency. At $60^{\circ}$ vane angle, the efficiency is higher than those measured at $40^{\circ}$ and 
$70^{\circ}$, while the $40^{\circ}$ vane angle setting seems to perform better than the $70^{\circ}$. The efficiency deficit for the $70^{\circ}$ vane angle compared to the optimum vane angle is approximately $17.3 \%, 10.1 \%$ and $17.7 \%$ for $40 \mathrm{~Hz}, 60 \mathrm{~Hz}$ and $80 \mathrm{~Hz}$ respectively. Such a penalty in efficiency could be attributed to the blockage effects due to closed nozzle settings, similar to what was found in the single-entry investigations [18]. The mass accumulation in the volume (volute + pipe) reduces the possible momentum imparted to the rotor with consequent lower power output.

\subsection{Further Considerations}

The analysis carried out within the current paper comes as a continuation of a similar study done on the same turbines configurations under steady-state conditions [1]. The results obtained in steadystate conditions showed that the mass flow parameters for the twin-entry are almost independent of the configuration and of the type of flow admission (partial or unequal admission [1]). A similar behaviour is not observed as the turbines starts to operate under unsteady conditions. Even though the hysteresis loops between the entries seem to have a fair degree of symmetry, there are still some issues, which need to be addressed in order to be able to make a final judgement over the turbine performance. These can be identified mainly in (1) the reliability of the quasi-steady assumption, for which there are still on-going debates but it is common to both single and twin-entry configurations, and (2) the physical approach in the evaluation of the performance parameters for a twin-entry turbine. Within the current paper, in accordance with previously published works [1, 23], a mass weighed averaged total temperatures and an area averaged pressure ratios were considered for the calculation of mass flow parameters. However, the complexity attributed to the mixing of the travelling pulses and the extra degree of freedoms due to the admission conditions (either inphase or out-of-phase) makes the assessment particularly complex. In this sense the experimental results presented here provide an initial and rather unique insight on the response of a variable geometry twin-entry turbine. The experimental results build up well with previously published works and they form a benchmark for future works. Currently on-going work within the Imperial 
College research group is focussing on 1D simulation in the aim to discover more physical insights of turbine behaviour under pulsating flow conditions.

\subsection{CONCLUSIONS}

The current paper discusses performance analysis of a twin-entry variable geometry turbine tested under pulsating flow conditions. The twin-entry turbine was designed in progression from singleentry nozzleless and nozzled turbines, while maintaining the main geometrical features in all cases. These were used as basis of comparison to gauge the operating variation and the associated twinentry turbine performance, under pulsating flow conditions. Some initial results of the nozzleless and nozzled single entry turbine are also shown as to allow readers to follow through the design progression.

For the optimum vane angle setting $\left(60^{\circ}\right)$ and in-phase flow condition, the overall flow capacity is larger than the equivalent quasi-steady. The encapsulation of the quasi-steady curve is only partially achieved and it occurs mainly in the low pressure region of the maps for low speeds and frequencies. A more appreciable level of encapsulation with the quasi-steady curve is achieved for the flow capacity owning to each limb; a similar shape for the hysteresis loop could be found for the two entries even though the outer entry (shroud-side) was found to operate at higher pressure ratios than the inner entry (hub-side). As for the out-of-phase conditions, the pulsating nature of the flow at staggered intervals, leads to a higher rate of filling and empty, and this could be observed in the occurrence of large hysteresis loop amplitude.

The quasi-steady assumption for the turbine efficiency under in-phase flow condition found to be only partially true. At 50\% equivalent speed and low frequency the cycle-averaged efficiency is approximately $25 \%$ lower than the quasi-steady whereas at high frequency the cycle-averaged and the quasi-steady efficiency are almost coincident ( $0.79 \%$ difference). Meanwhile at $80 \%$ equivalent speed, the quasi-steady assumption is satisfied at low and high frequencies $(40 \mathrm{~Hz}$ and $80 \mathrm{~Hz})$, whereas a transition region from quasi-steady to fully unsteady was observed at $60 \mathrm{~Hz}$. 
The quasi-steady assumption for the turbine efficiency under out-of-phase flow condition was found to be unsatisfied - a difference from $18 \%$ to more than $30 \%$ was measured for both $50 \%$ and $80 \%$ equivalent speed. The full admission quasi-steady efficiency is not fully representative of the out-ofphase flow condition in the turbine, which at each instant in time is more likely to act as in partial admission conditions. At $80 \%$ equivalent speed, the ratio between the cycle-averaged and the quasisteady efficiency deviates only by few percentage points $(1.03,0.85$ and 0.92 at $40 \mathrm{~Hz}, 60 \mathrm{~Hz}$ and $80 \mathrm{~Hz}$ respectively) while at $50 \%$ equivalent speed, an improvement of almost 10 percentage points could be measured. The ratio between the cycle-averaged and the quasi-steady assumption passed from $0.67,0.70$ and 0.82 for the full admission to $0.81,0.77$ and 0.98 for partial admission, at $40 \mathrm{~Hz}, 60 \mathrm{~Hz}$ and $80 \mathrm{~Hz}$ respectively.

The effects of vane angle on the cycle-averaged efficiency provided different response depending on the pulse flow. In-phase flow showed that at lower frequencies the close vane position $\left(60^{\circ}\right.$ and $70^{\circ}$ vane angle) is detrimental to the efficiency compared to the fully open position ( $40^{\circ}$ vane angle). The same does not occur in out-of-phase flow where higher efficiency was found for the optimum vane angle $\left(60^{\circ}\right.$ vane angle). This agrees with the findings found in the steady-state testing which show a higher efficiency for the optimum vane angle.

\section{ACKNOWLEDGEMENTS}

The authors would like to acknowledge Ricardo plc, Ford Motor Company Ltd and University of Brighton. This consortium along with Imperial College is part of funded program (TSB) named VERTIGO (Virtual Emission Research Tools and Integration).

\section{REFERENCES}

[1] Romagnoli A, Rajoo S, Martinez-Botas RF. Turbine performance studies for automotive turbochargers Part one: steady analysis. $9^{\text {th }}$ Int. Conf. on Turbocharging and Turbochargers, Instn. Mech. Engr, 2009. 
[2] Wallace FJ, Blair GP. The pulsating flow performance of inward radial-flow turbines. Trans. ASME 65- GTP. 21, pp. 1-19, 1965.

[3] Benson RS, Scrimshaw KH. An experimental investigation of non-steady flow in a radial gas turbine. Proc. Instn. Mech. Engr., Vol. 180 (3J), 1965-1966.

[4] Wallace FJ, Adgey JM, Blair GP. Performance of inward flow turbines under unsteady flow conditions. Proc. Instn. Mech. Engr., 184(1), 1969-1970.

[5] Miyashita T, Tomita T, Ishihara D. Performance of inward radial flow turbines under unsteady flow conditions. IHI Engineering Review, 7(1), 1974.

[6] Benson RS. Non steady flow in a turbocharger nozzleless radial gas Turbine. Trans. SAE, Paper No. 740739, 1974.

[7] Kosuge H, Yamanaka N, Ariga I, Watanabe I. Performance of radial flow turbines under pulsating flow conditions. Trans. ASME, Vol. 98, pp. 53-59, 1976.

[8] Capobianco M, Gambarotta A, Cipolla G. Influence of the pulsating flow operation on the turbine characteristics of a small internal combustion engine turbocharger. Proc. Instn. Mech. Engr., Paper No. C372/019, 1989.

[9] Capobianco M, Gambarotta A. Unsteady flow performance of turbocharger radial turbines. $4^{\text {th }}$ Int. Conf. on Turbocharging and Turbochargers, Instn. Mech. Engr., Paper No. C405/017, 1990.

[10] Capobianco M, Gambarotta A. Variable geometry and waste-gated automotive turbocharges: Measurements and comparison of turbine performance. J. Eng. Gas Turbines and Power, Vol. 114, pp. 553-560, 1992.

[11] Winterbone DE, Nikpour B, Frost H. A Contribution to the Understanding of Turbocharger Turbine Performance in Pulsating Flow. Proc. Instn. Mech. Engr., Paper No. C433/011, 1991.

[12] Winterbone DE, Pearson RJ. Turbocharger turbine performance under unsteady flow - a review of experimental results and proposed models. $6^{\text {th }}$ Int. Conf. on Turbocharging and Turbochargers, Instn. Mech. Engr., Paper No. C554/031/98, 1998. 
[13] Dale A, Watson N. Vaneless Radial Turbocharger Turbine Performance'. $3^{\text {rd }}$ International Conference on Turbocharging and Turbochargers. Instn. Mech. Engr., Paper No. C110/86, 1986.

[14] Dale AP. Radial, vaneless, turbocharger turbine performance. Ph. D. Thesis. Imperial College of Science, Technology, and Medicine, University of London, UK, 1990.

[15] Nikpour B. Measurement of the performance of a radial inflow turbine. Ph. D. Thesis. University of Manchester Institute of Science and Technology, UK, 1990.

[16] Baines NC, Hajilouy-Benisi A, Yeo JH. The Pulse Flow Performance and Modelling of Radial Inflow Turbines. $5^{\text {th }}$ International Conference on Turbocharging and Turbochargers, Instn. Mech. Engr., Paper No. C484/006/94, 1994.

[17] Szymko S, Martinez-Botas RF, Pullen KR. Experimental Evaluation of Turbocharger Turbine Performance under Pulsating Flow Conditions. Trans. ASME Turbo Expo, GT 2005-68878, 2005.

[18] Potter CM, Wiggert CD. Mechanics of Fluids. Brooks/Cole Thomson Learning, USA, 2002.

[19] Szymko S. The Development of an Eddy Current Dynamometer for Evaluation of Steady and Pulsating Turbocharger Turbine Performance. Ph. D. Thesis. Imperial College of Science, Technology, and Medicine, University of London, UK, 2006.

[20] Rajoo S. Steady and pulsating performance of a variable geometry mixed-flow turbocharger turbine. Ph. D. Thesis. University of Manchester Institute of Science and Technology, UK, 2007.

[21] Rajoo S. Martinez-Botas RF. Unsteady Effect in a Nozzled Turbocharged Turbine. J. Turbomach. Vol. 132, Issue 3, 2010.

[22] Karamanis N, Martinez-Botas RF. Mixed-Flow Turbines for Automotive Turbochargers: Steady and unsteady Performance. IMechE Int. J. Eng. Res., Vol. 3 No.3, 2002.

[23] Whitfield A, Baines NC. Design of Radial Turbomachines. Longman Scientific \& technical, Wiley Edition, 1990. 


\section{TABLES}

\section{Table 1}

Energy weighed cycle-averaged values of velocity ratio and efficiency for single-entry nozzled and nozzleless turbine, $80 \%$ equivalent speed conditions, Szymko (2006)

\begin{tabular}{cccc}
\hline Frequency \& Configuration & $\mathbf{U}_{\mathbf{C}} \mathbf{C}_{\text {isent }}$ & $\boldsymbol{\eta}_{\text {cycle-avg }}$ & $\eta_{\text {quasi-steady }}$ \\
\hline $40 \mathrm{~Hz} 50 \mathrm{deg}$ & 0.662 & $0.607_{(-3.1 \%)}$ & 0.638 \\
$40 \mathrm{~Hz}$ nozzleless & 0.624 & $0.626_{(-4.6 \%)}$ & 0.672 \\
$60 \mathrm{~Hz} 50 \mathrm{deg}$ & 0.684 & $0.69_{(+4.2 \%)}$ & 0.648 \\
$60 \mathrm{~Hz}$ nozzleless & 0.653 & $0.691_{(+0.8 \%)}$ & 0.683 \\
\hline
\end{tabular}

Table 2

Comparison of energy weighed cycle-averaged and quasi-steady efficiency

\begin{tabular}{|c|c|c|c|c|c|c|c|c|}
\hline \multicolumn{5}{|c|}{$60^{\circ}$ vane angle } & \multicolumn{4}{|c|}{ In-Phase } \\
\hline & \multicolumn{4}{|c|}{$50 \%$ Equivalent Speed } & \multicolumn{4}{|c|}{$80 \%$ Equivalent Speed } \\
\hline & $\mathrm{U} / \mathrm{C}_{\text {isent }}$ & $\eta_{\text {cycle-avg }}$ & $\eta_{\text {quasi-steady }}$ & $\Delta \eta$ & $\mathrm{U} / \mathrm{C}_{\text {isent }}$ & $\eta_{\text {cycle-avg }}$ & $\eta_{\text {quasi-steady }}$ & $\Delta \eta$ \\
\hline $40 \mathrm{~Hz}$ & 0.542 & 0.472 & 0.631 & $-26.2 \%$ & 0.640 & 0.835 & 0.784 & $6.1 \%$ \\
\hline $60 \mathrm{~Hz}$ & 0.503 & 0.456 & 0.611 & $-26.4 \%$ & 0.596 & 0.616 & 0.768 & $-24.6 \%$ \\
\hline \multicolumn{5}{|c|}{$60^{\circ}$ vane angle } & & \multicolumn{3}{|c|}{ Out-of-Phase } \\
\hline & \multicolumn{4}{|c|}{$50 \%$ Equivalent Speed } & \multicolumn{4}{|c|}{$80 \%$ Equivalent Speed } \\
\hline $40 \mathrm{~Hz}$ & 0.587 & 0.434 & 0.647 & -23.1 & 0.595 & 0.631 & 0.768 & $-18.2 \%$ \\
\hline $60 \mathrm{~Hz}$ & 0.464 & 0.415 & 0.586 & $-30.3 \%$ & 0.587 & 0.520 & 0.763 & $-32.2 \%$ \\
\hline
\end{tabular}

Table 3

Comparison between cycle-averaged and quasi-steady efficiency considering full and partial admission assumption for the quasi-steady value

Out-of-phase flow

(quasi-steady assumption based on partial admission condition)

\begin{tabular}{ccccccccccccc}
\hline \multicolumn{10}{c}{ 50\% Equivalent Speed } & \multicolumn{10}{c}{ 80\% Equivalent Speed } \\
\hline & ${\mathrm{U} / \mathrm{C}_{\text {isent }}}$ & $\eta_{\text {cycle-avg }}$ & $\eta_{\mathrm{qs}, \text { full }}$ & $\eta_{\text {ratio }}$ & $\eta_{\mathrm{qs}, \text { partial }}$ & $\eta_{\text {ratio }}$ & $\mathrm{U} / \mathrm{C}_{\text {isent }}$ & $\eta_{\text {cycle-avg }}$ & $\eta_{\text {qs,full }}$ & $\eta_{\text {ratio }}$ & $\eta_{\text {qs, partial }}$ & $\eta_{\text {ratio }}$ \\
\hline $40 \mathrm{~Hz}$ & 0.587 & 0.434 & 0.647 & 0.67 & 0.530 & 0.81 & 0.595 & 0.631 & 0.768 & 0.82 & 0.607 & 1.03 \\
$60 \mathrm{~Hz}$ & 0.464 & 0.415 & 0.586 & 0.70 & 0.533 & 0.77 & 0.587 & 0.520 & 0.763 & 0.68 & 0.607 & 0.85 \\
$80 \mathrm{~Hz}$ & 0.567 & 0.526 & 0.641 & 0.82 & 0.534 & 0.98 & 0.577 & 0.560 & 0.757 & 0.73 & 0.608 & 0.92 \\
\hline
\end{tabular}


Table 4

Energy weighed cycle-averaged efficiency for different vane angles

$\mathbf{5 0 \%}$ Equivalent Speed

In-phase

\begin{tabular}{|c|c|c|c|c|c|c|}
\hline \multicolumn{3}{|c|}{$40^{\circ}$ vane angle } & \multirow{2}{*}{$\frac{\mathbf{6 0}^{\circ} \text { vane angle }}{U / C_{\text {isent }}}$} & \multicolumn{3}{|c|}{$70^{\circ}$ vane angle } \\
\hline & $\mathrm{U} / \mathrm{C}_{\text {isent }}$ & $\eta_{\text {cycle-avg }}$ & & $\eta_{\text {cycle-avg }}$ & $\mathrm{U} / \mathrm{C}_{\text {isent }}$ & $\eta_{\text {cycle-avg }}$ \\
\hline $40 \mathrm{~Hz}$ & 0.593 & 0.593 & 0.542 & 0.472 & 0.51 & 0.470 \\
\hline $60 \mathrm{~Hz}$ & 0.548 & 0.590 & 0.503 & 0.456 & 0.541 & 0.463 \\
\hline $80 \mathrm{~Hz}$ & 0.519 & 0.347 & 0.533 & 0.631 & 0.487 & 0.288 \\
\hline \multicolumn{5}{|c|}{$80 \%$ Equivalent Speed } & \multicolumn{2}{|c|}{ Out-of-phase } \\
\hline & $40^{\circ}$ vane angle & & $60^{\circ}$ vane angle & & $70^{\circ}$ vane : & \\
\hline & $\mathrm{U} / \mathrm{C}_{\text {isent }}$ & $\eta_{\text {cycle-avg }}$ & $\mathrm{U} / \mathrm{C}_{\text {isent }}$ & $\eta_{\text {cycle-avg }}$ & $\mathrm{U} / \mathrm{C}_{\text {isent }}$ & $\eta_{\text {cycle-avg }}$ \\
\hline $40 \mathrm{~Hz}$ & 0.556 & 0.425 & 0.587 & 0.434 & 0.472 & 0.261 \\
\hline $60 \mathrm{~Hz}$ & 0.524 & 0.344 & 0.464 & 0.412 & 0.478 & 0.311 \\
\hline $80 \mathrm{~Hz}$ & 0.587 & 0.433 & 0.567 & 0.526 & 0.485 & 0.349 \\
\hline
\end{tabular}




\section{FIGURES}

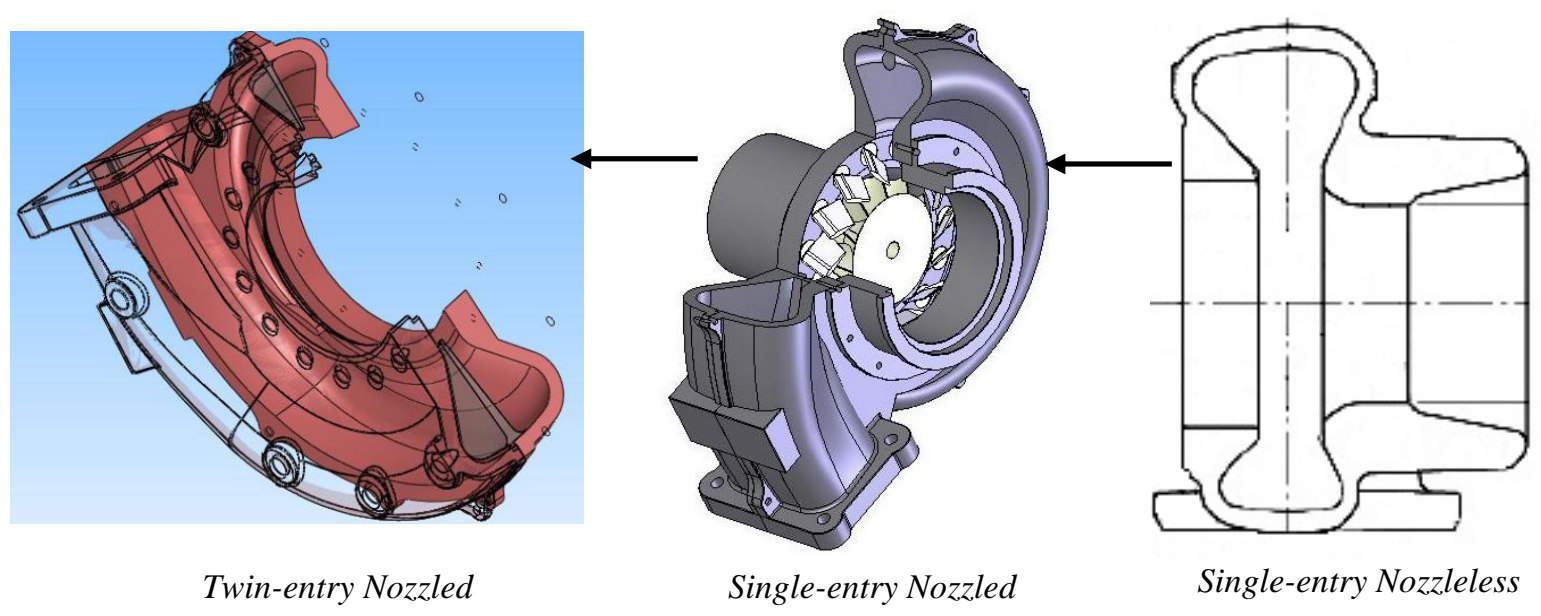

Fig. 1. Turbine volutes used for the current study

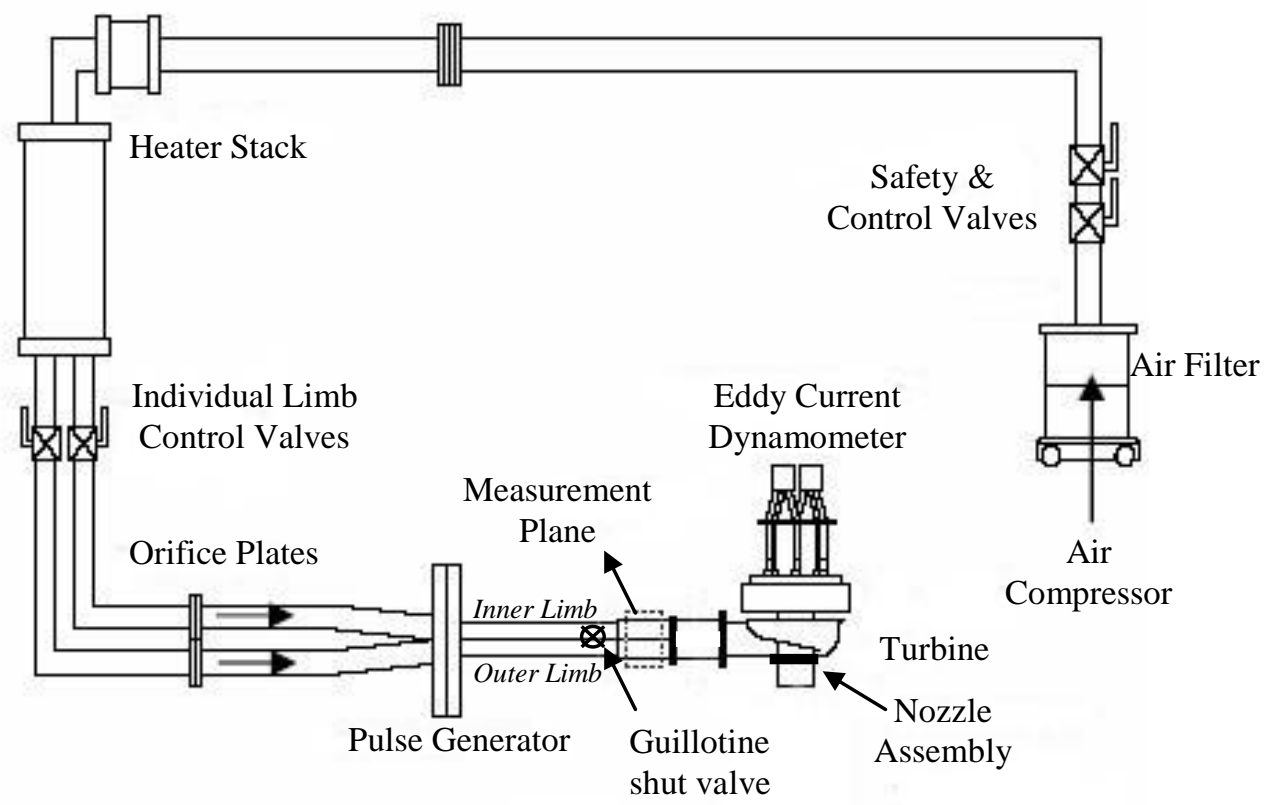

Fig. 2. Turbocharger test-rig schematic diagram 

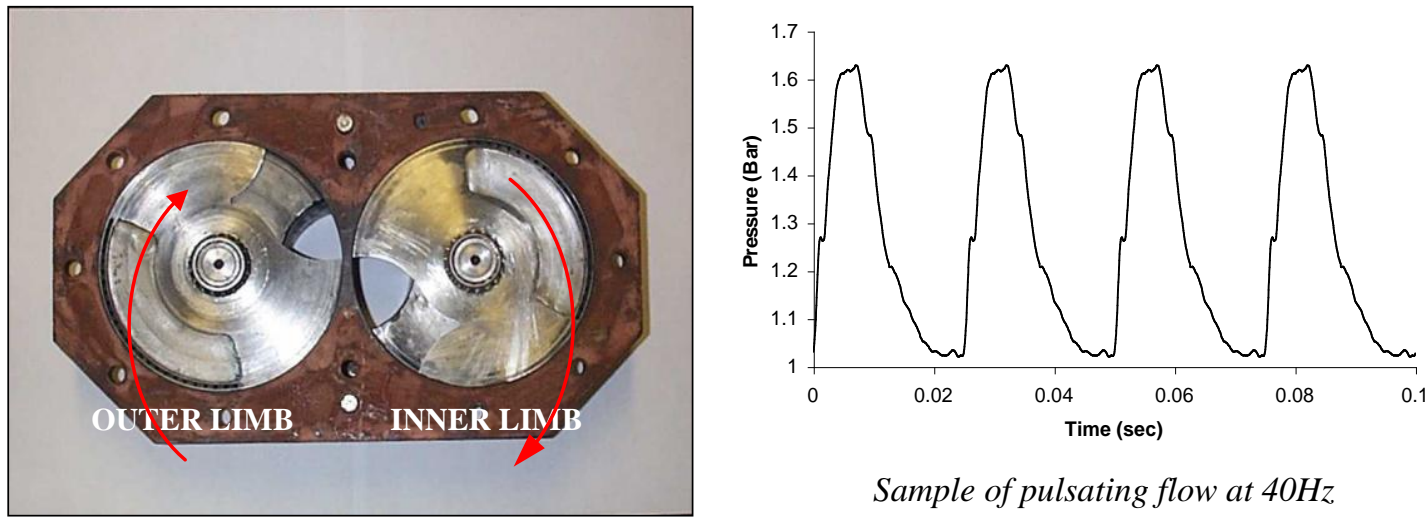

Sample of pulsating flow at $40 \mathrm{~Hz}$

Fig. 3. Rotating chopper plate for the air pulse generator to experimentally simulate exhaust gas pulsation
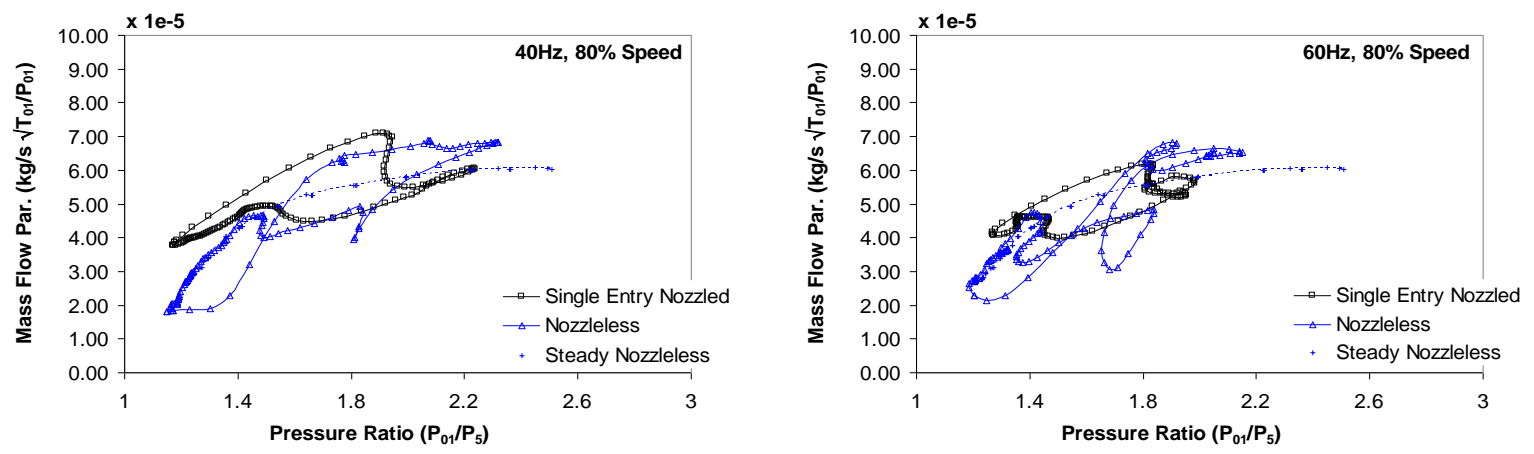

Fig. 4. Comparison of the mass flow parameter vs. pressure ratio curves between the single-entry nozzled and nozzleless turbine at $40 \& 60 \mathrm{~Hz}, 80 \%$ equivalent speed condition [19] 

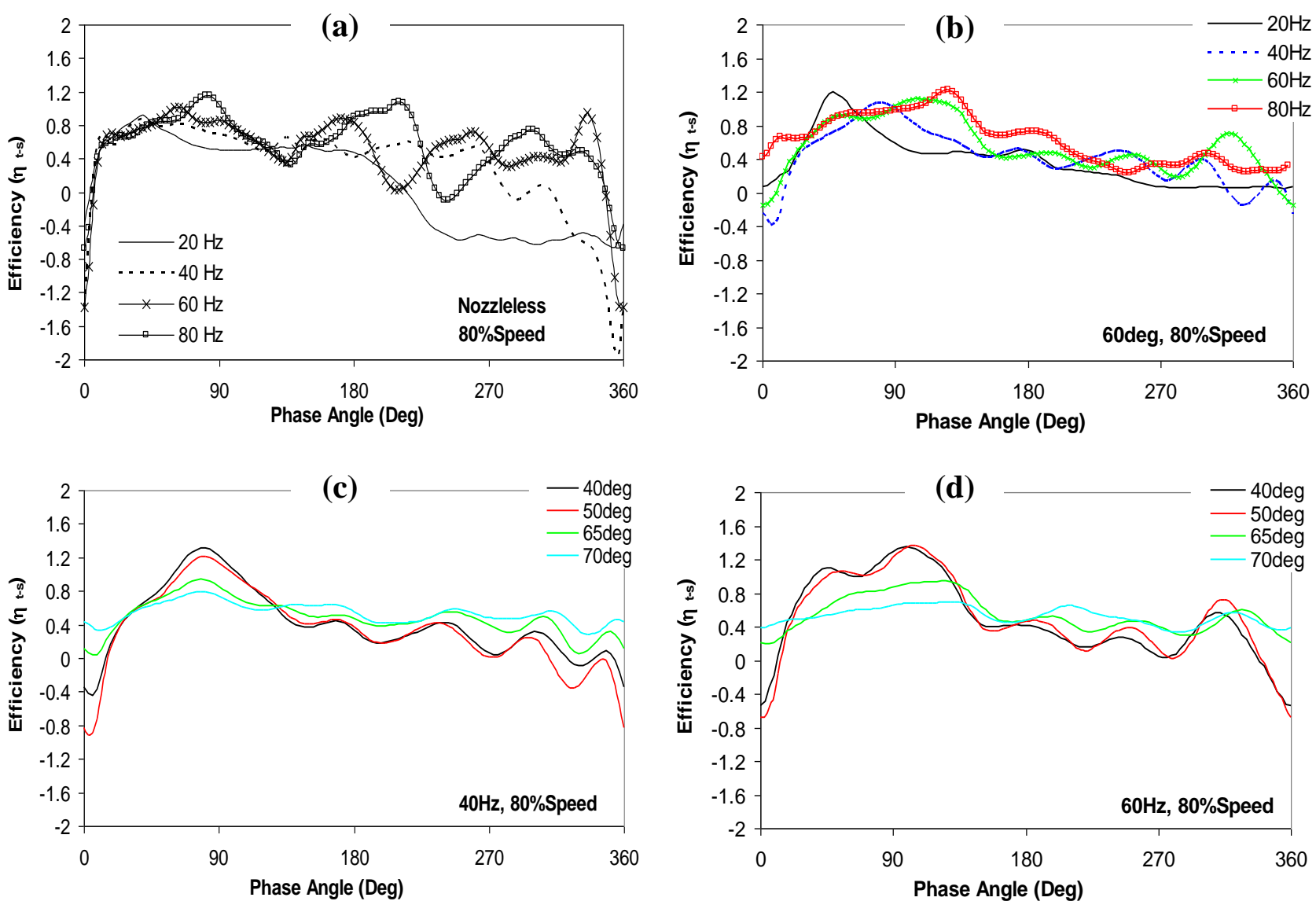

Fig. 5. Comparison of the efficiency curves between the nozzled single-entry and nozzleless turbine for different nozzle vane angles, different flow frequencies and $80 \%$ equivalent speed condition [19]
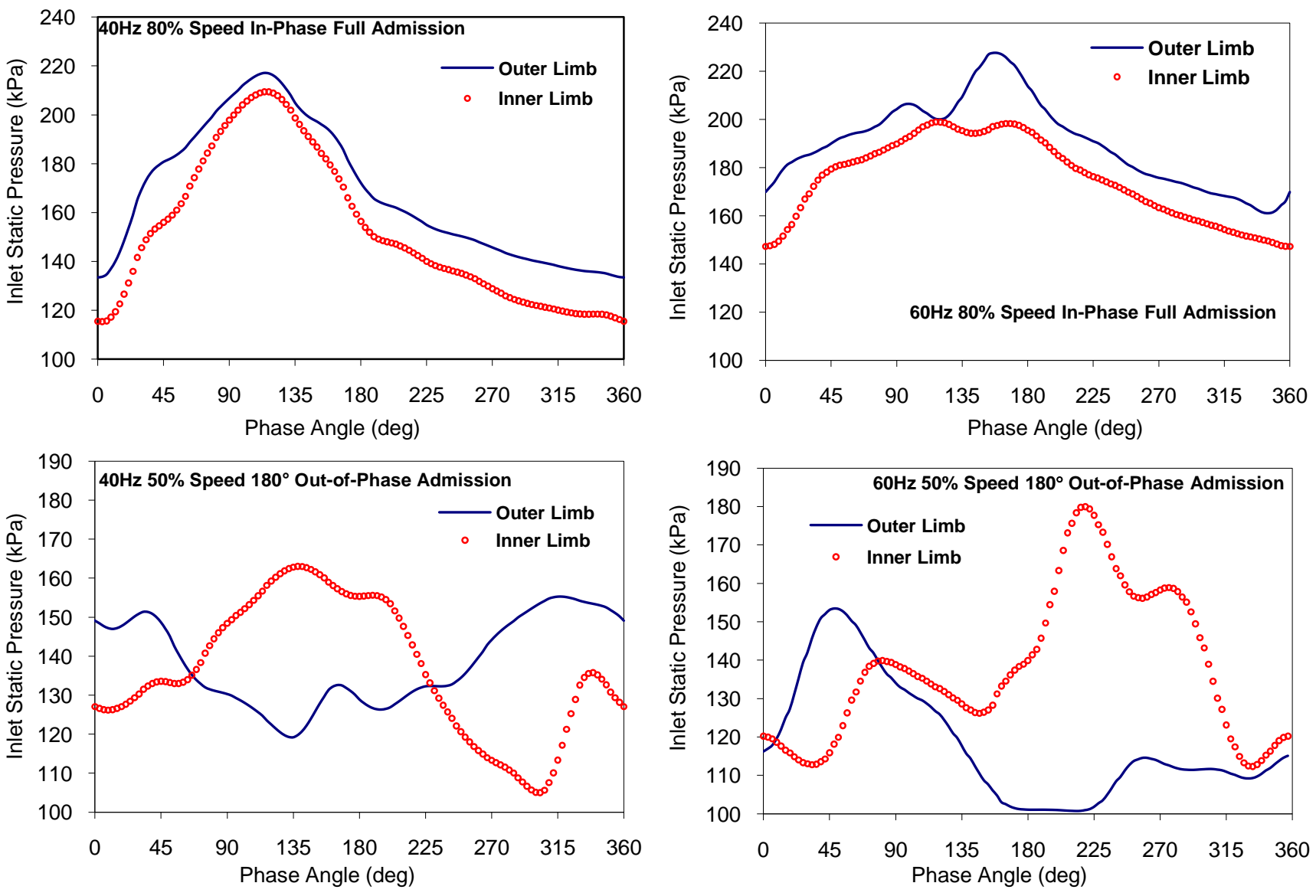

Fig. 6. Twin-entry turbine typical inlet static pressure profiles for in-phase and $180^{\circ}$ out-of-phase admission: given for individual entries, inner and outer limbs 

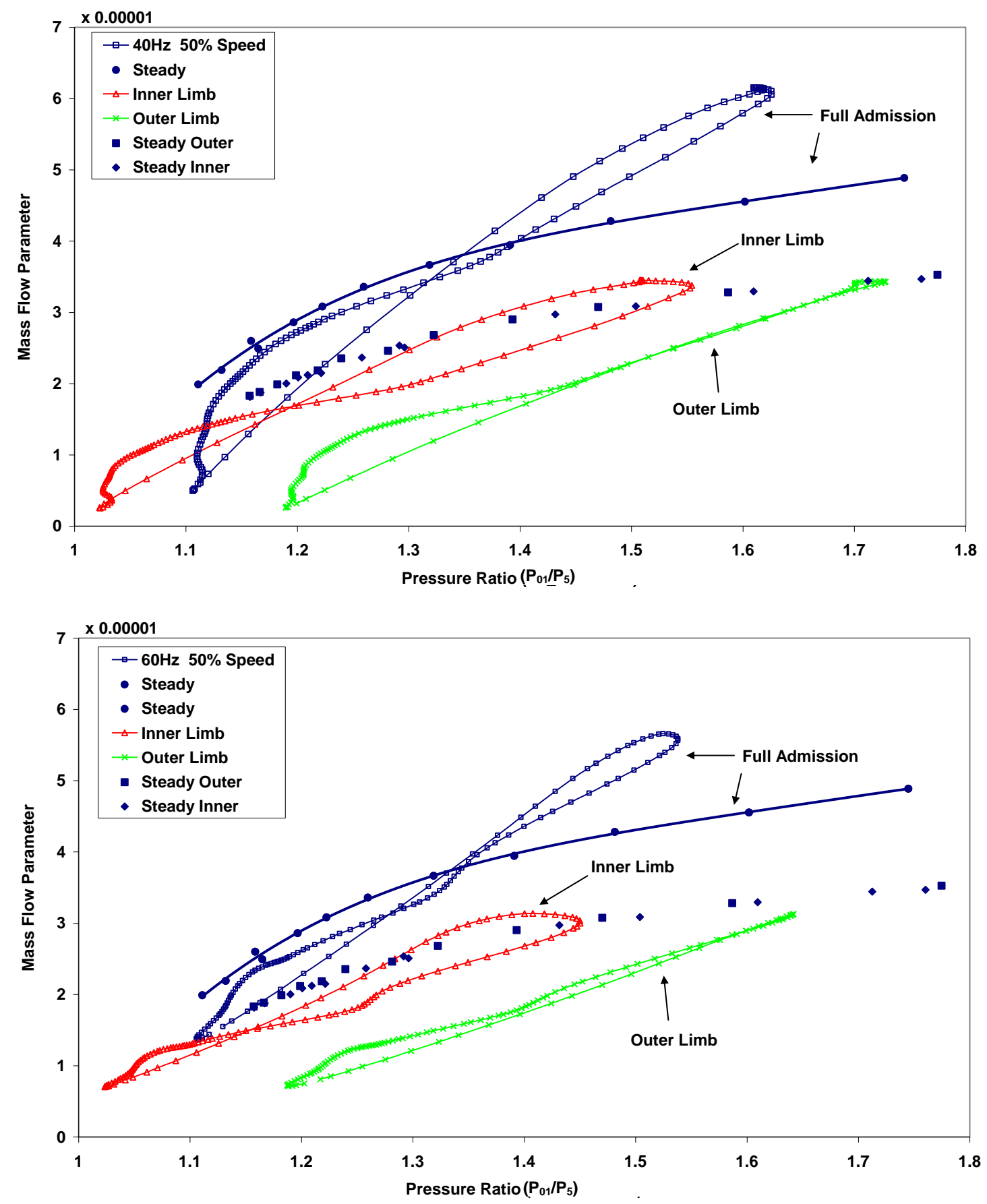

Fig. 7. Swallowing capacity of twin-entry turbine at $50 \%$ equivalent speed and inphase full admission: given for individual entries, inner and outer limbs as well as mass averaged combination 

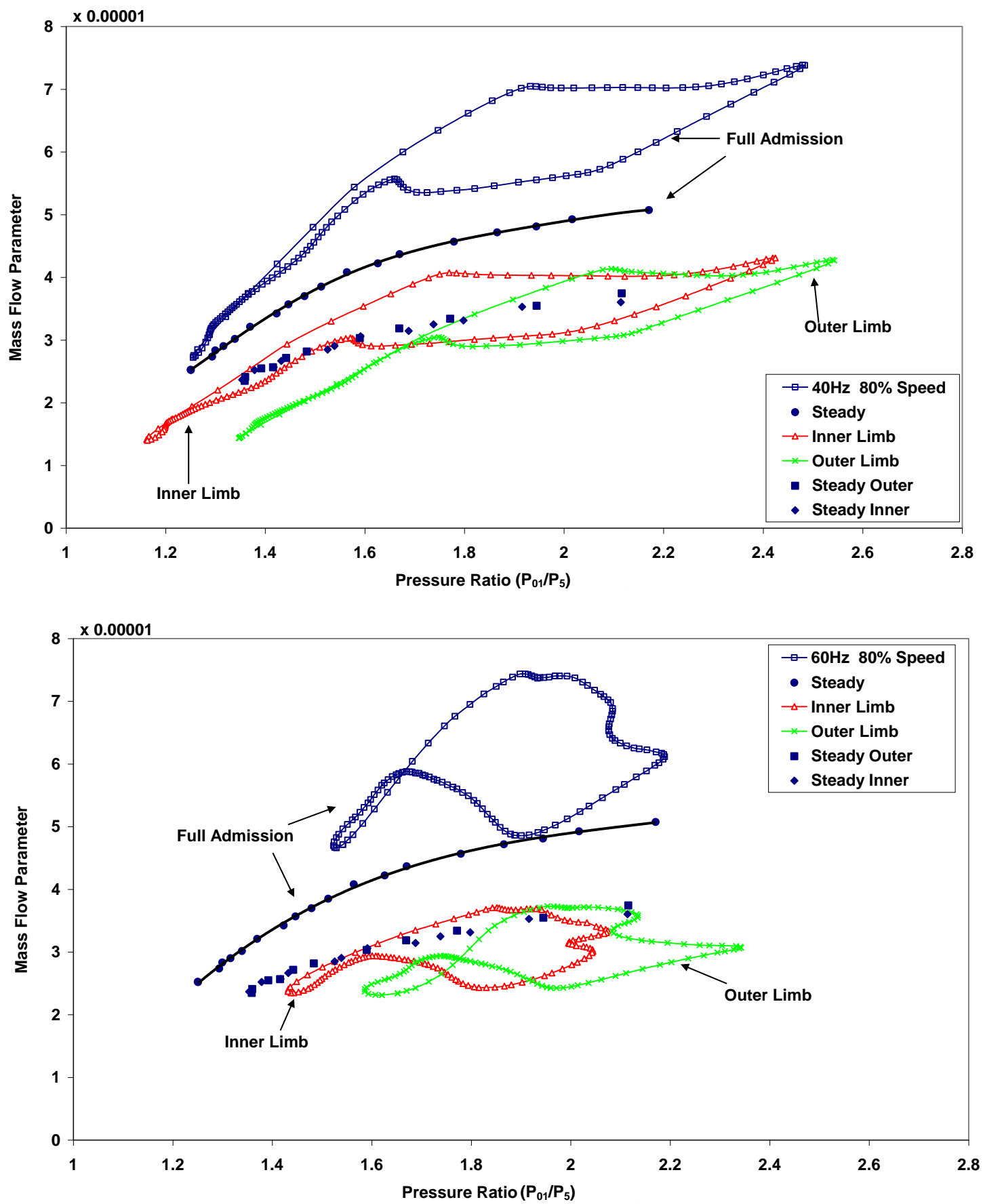

Fig. 8. Swallowing capacity of twin-entry turbine at $80 \%$ equivalent speed and in-phase full admission: given for individual entries, inner and outer limbs as well as mass averaged combination 

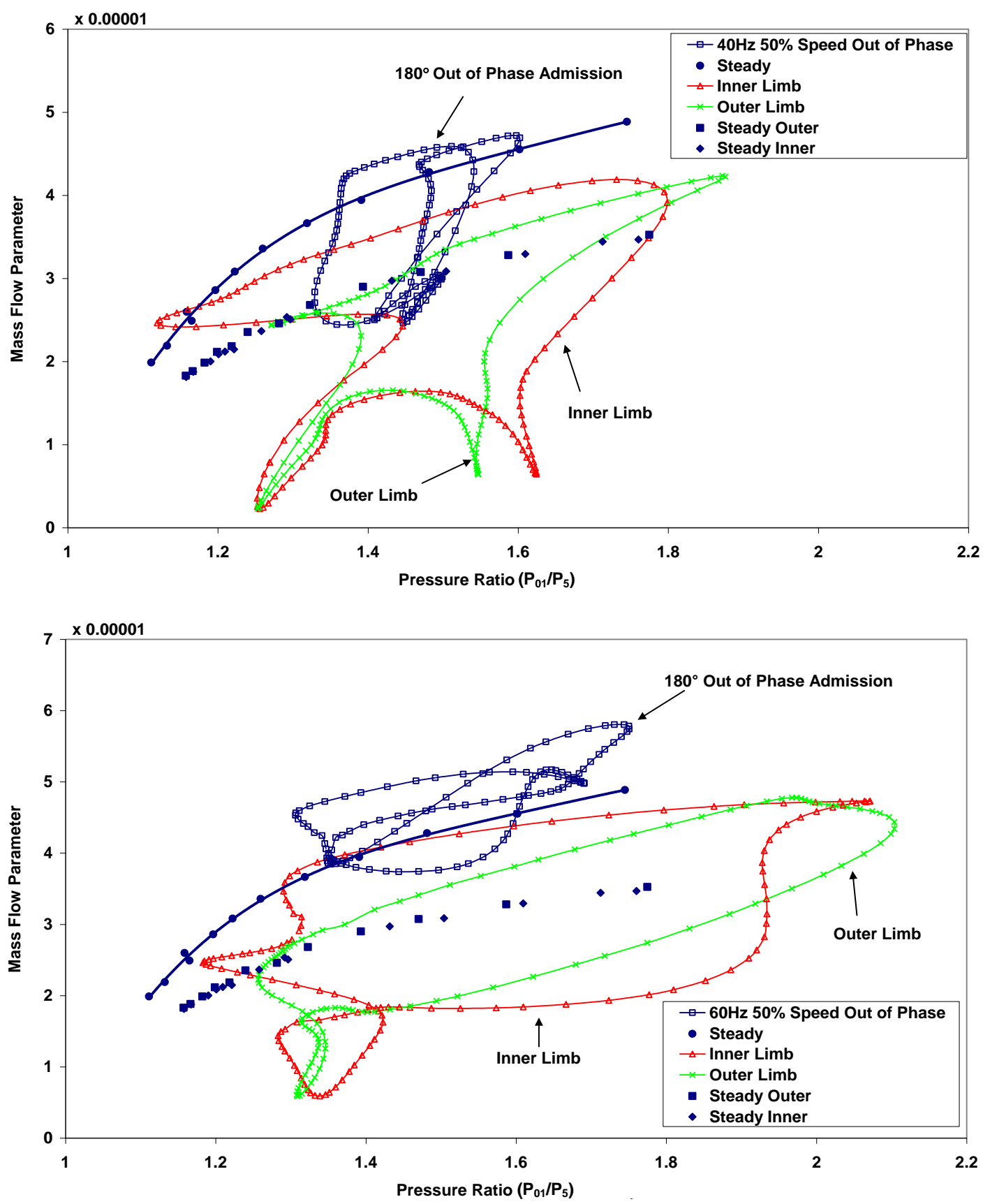

Fig. 9. Swallowing capacity of twin-entry turbine at 50\% equivalent speed and $180^{\circ}$ out-of-phase admission: given for individual entries, inner and outer limbs as well as mass averaged combination 

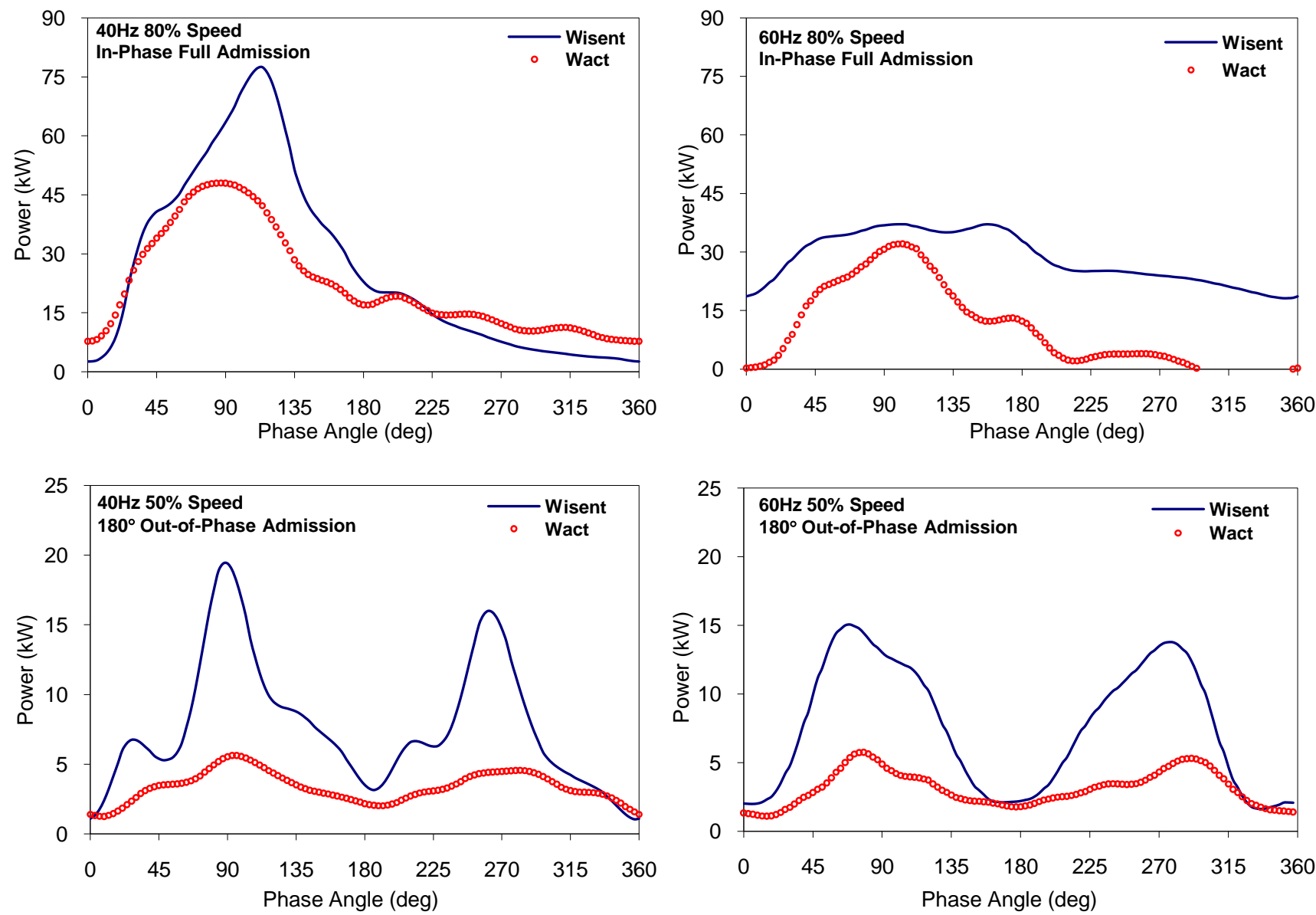

Fig. 10. Twin-entry turbine isentropic and actual power profiles for in-phase and $180^{\circ}$ outof-phase admissions: given for individual entries, inner and outer limbs 

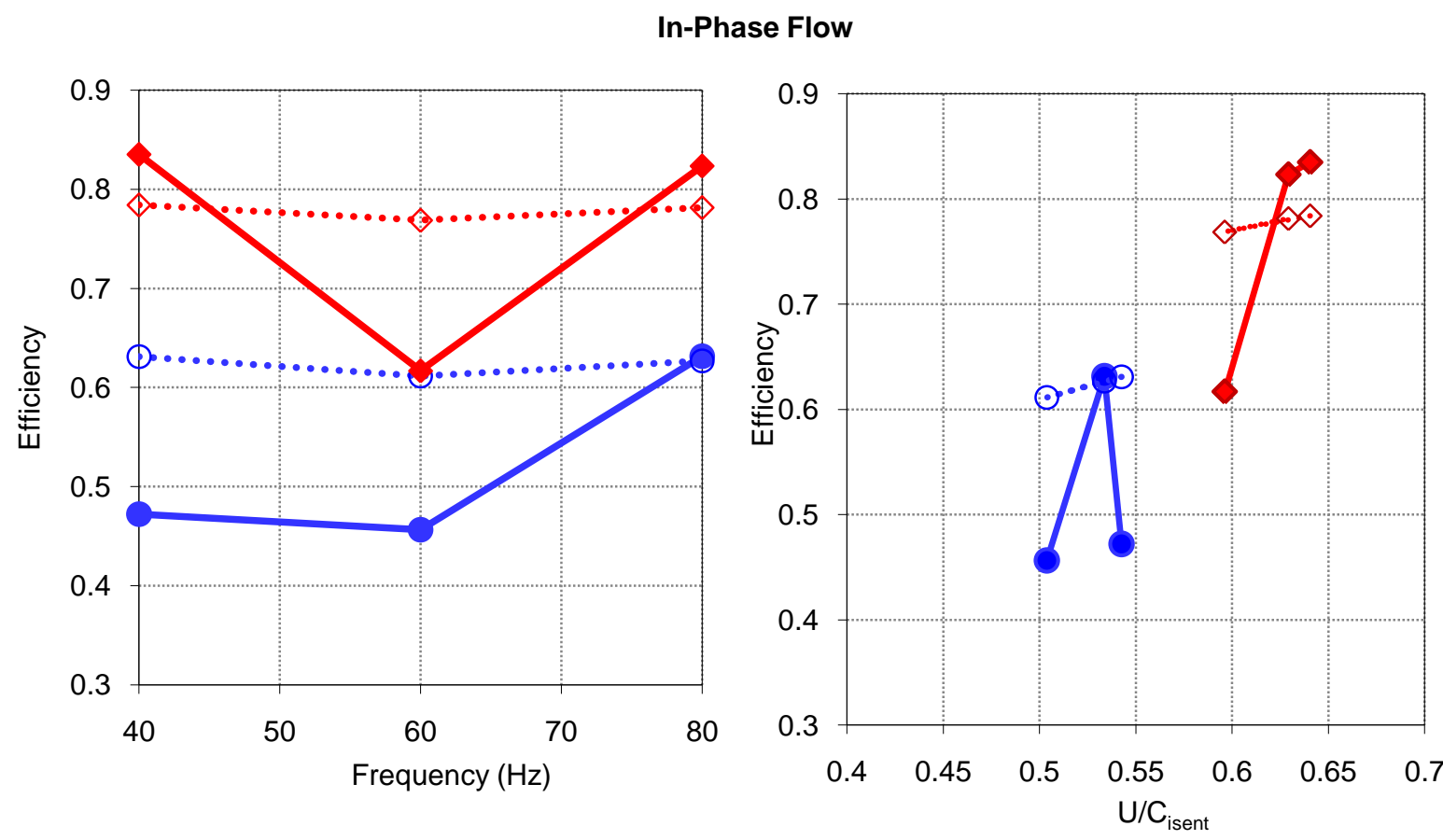

$\longrightarrow$ Cycle avrg eff - $50 \%$ Equiv Speed
$\longrightarrow$ Cycle avrg eff - $\quad 80 \%$ Equiv Speed

•.... Quasi-steady - 50\% Equiv Speed

...•... Quasi-steady - 80\% Equiv Speed

Fig. 11. Comparison cycle-averaged vs. quasi-steady efficiency for the in-phase flow at $50 \%$ and $80 \%$ equivalent speed for $60^{\circ}$ vane angle

\section{Out-of-Phase Flow}

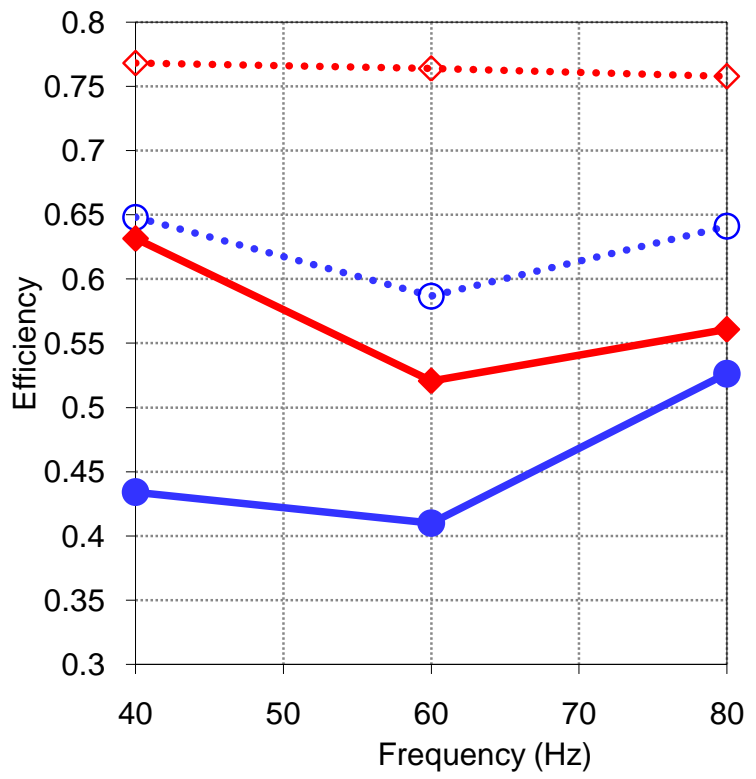

-Cycle avrg eff - 50\% Equiv Speed

$\longrightarrow$ Cycle avrg eff - $80 \%$ Equiv Speed

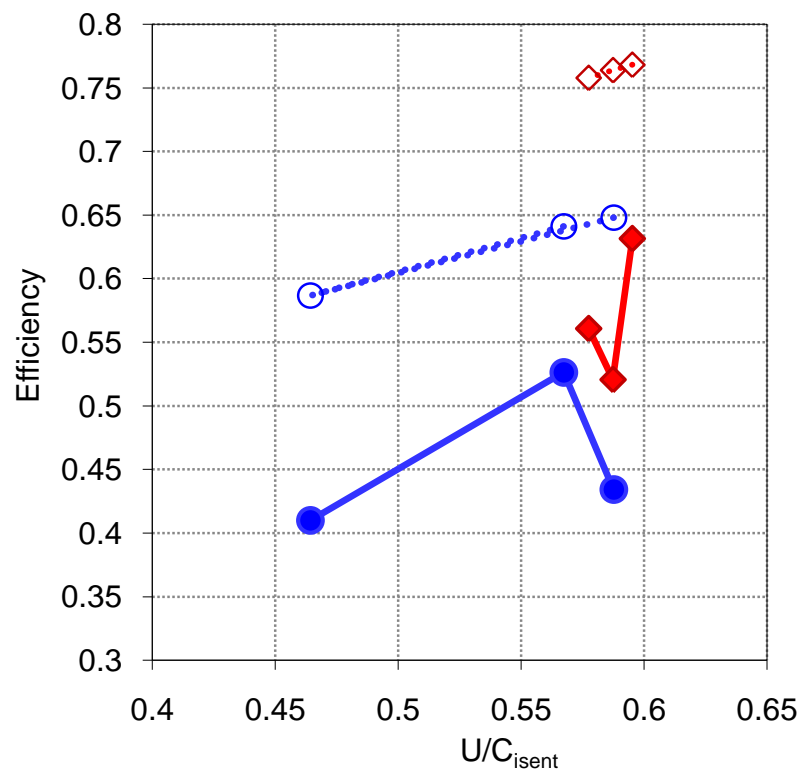

...0.. Quasi-steady - 50\% Equiv Speed

...४... Quasi-steady - 80\% Equiv Speed

Fig. 12. Comparison cycle-averaged vs. quasi-steady efficiency for the out-of-phase flow at $50 \%$ and 80 equivalent speed for $60^{\circ}$ vane angle 


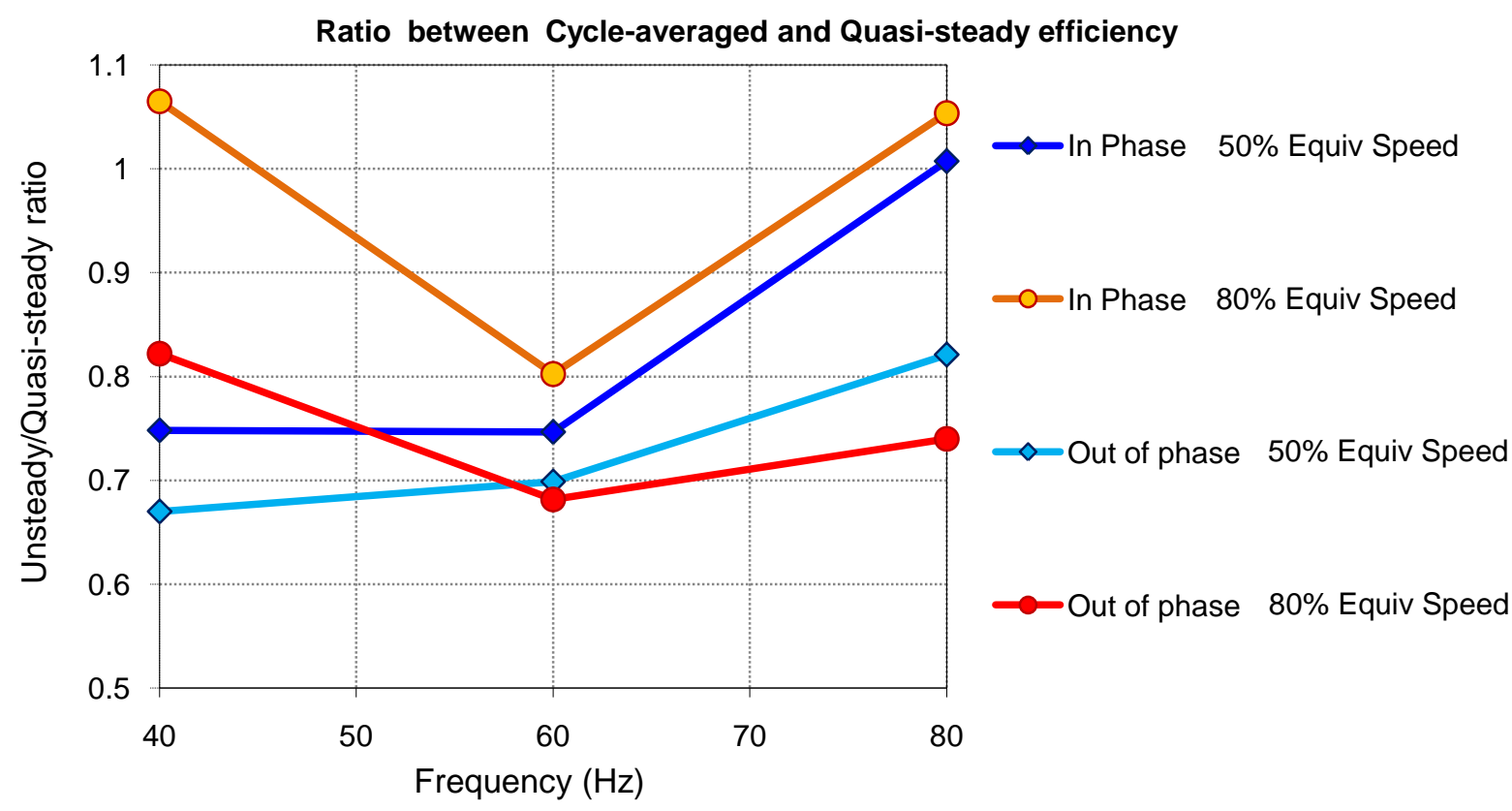

Fig. 13. Ratio between cycle-averaged and quasi-steady efficiency for the in-phase and out-of-phase flow at $50 \%$ and 80 equivalent speed

In Phase Flow

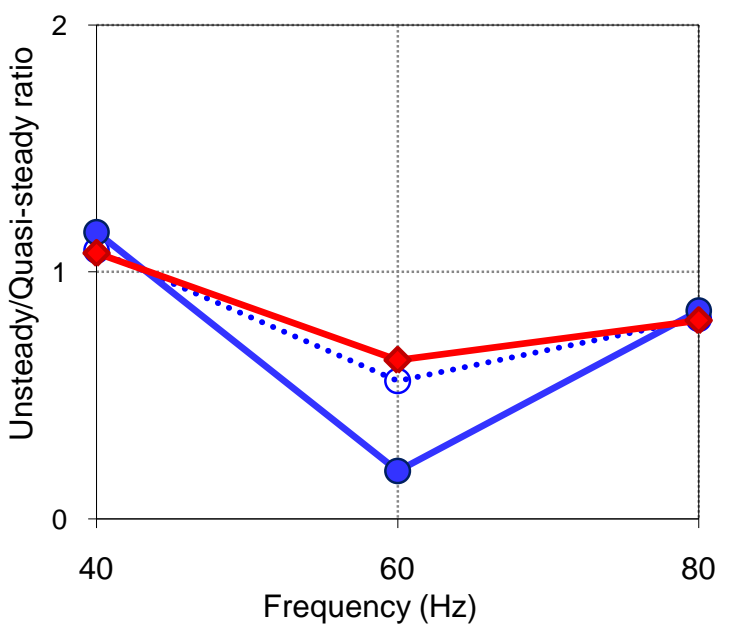

...... Wis ratio $\longrightarrow$ Wact ratio $\longrightarrow$ Mass flow ratio
Out of Phase Flow

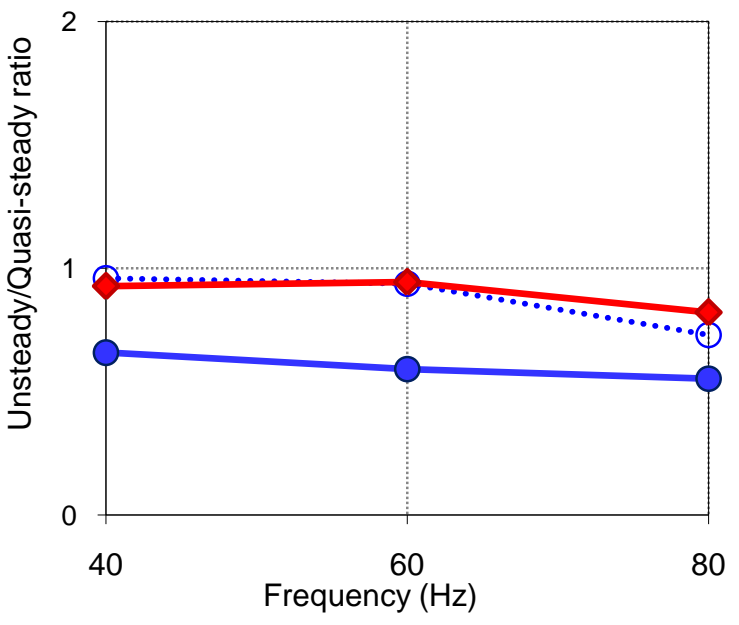

Fig. 14. Ratio cycle-averaged and quasi-steady power and mass flow rate for the in-phase and outof-phase flow at $80 \%$ equivalent speed and $60^{\circ}$ vane angle 


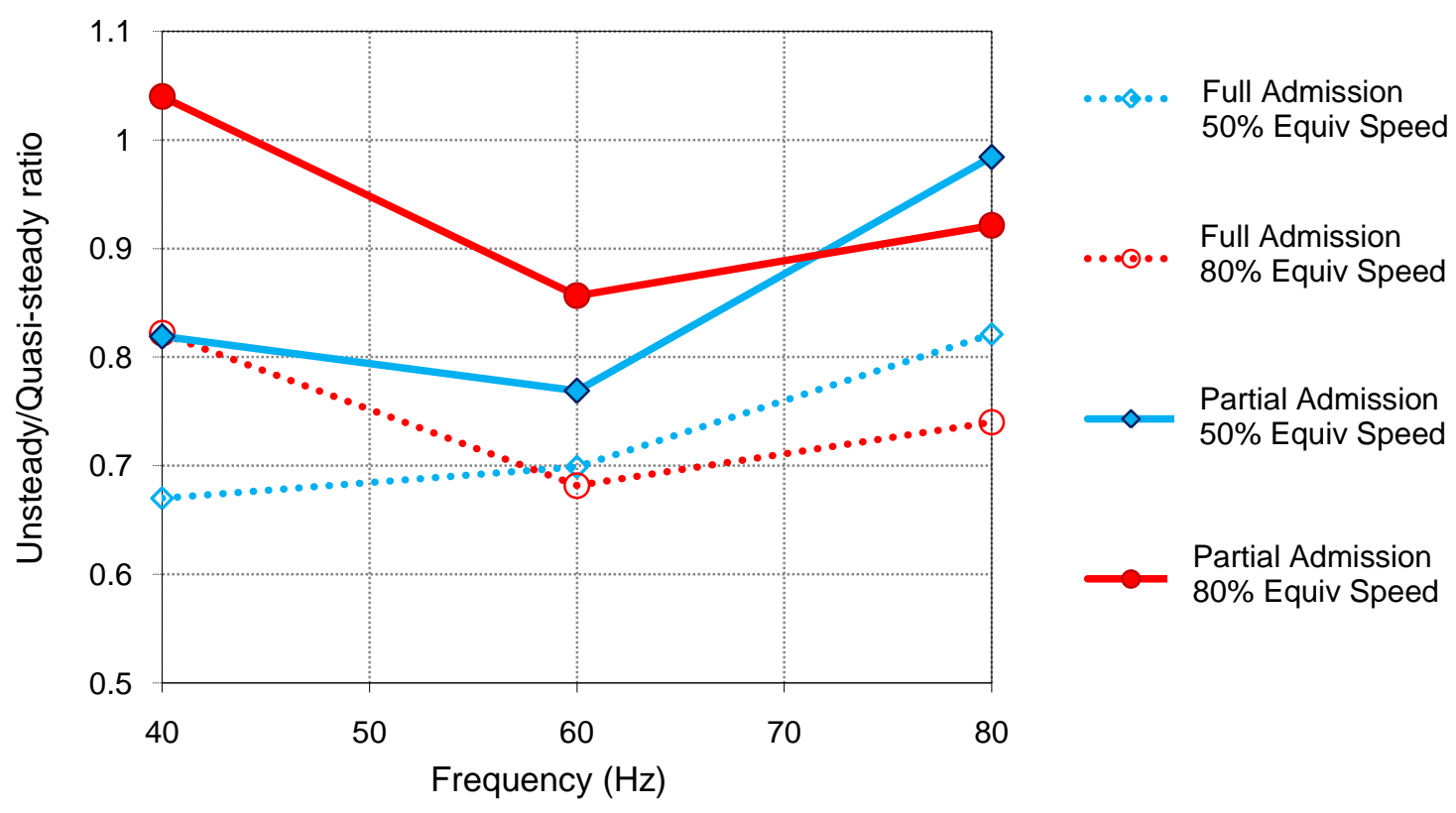

Fig. 15. Ratio of cycle-averaged and quasi-steady efficiency for the out-of-phase flow at $50 \%$ and $80 \%$ equivalent speed, obtained using the full and partial admission quasi-steady value
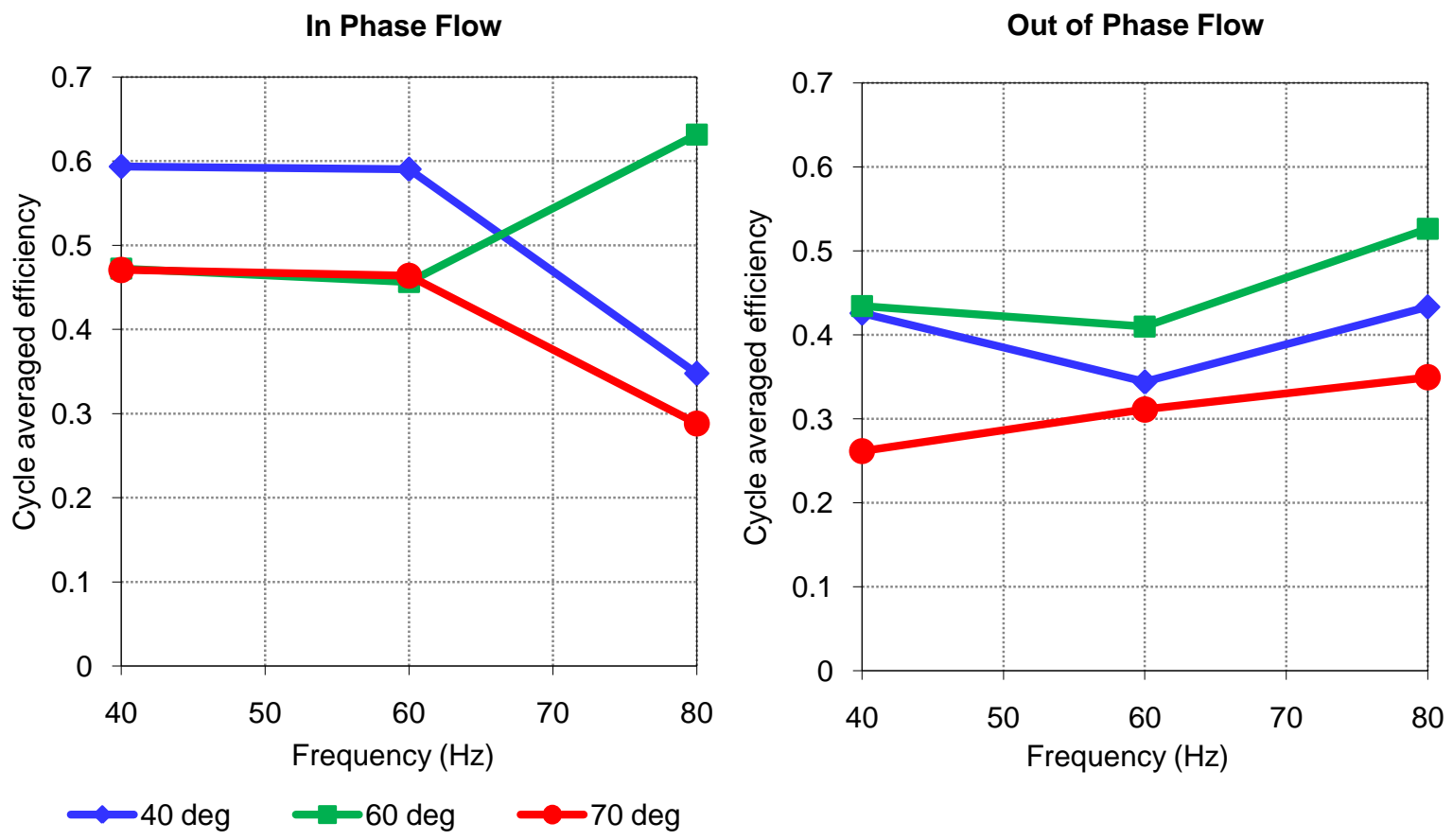

Fig. 16. Comparison of cycle-averaged efficiency for different vane angles $\left(40^{\circ}, 60^{\circ}\right.$ and $\left.70^{\circ}\right)$ for the in-phase and out-of-phase flow at $50 \%$ equivalent speed 